\title{
The impact of distinct anthropogenic and vegetation features on urban warming
}

\author{
Soe W. Myint • Elizabeth A. Wentz • \\ Anthony J. Brazel · Dale A. Quattrochi
}

Received: 1 April 2012/Accepted: 1 March 2013/Published online: 19 March 2013

(C) The Author(s) 2013. This article is published with open access at Springerlink.com

\begin{abstract}
We investigate the direct relationship between detailed urban land cover classes, derived from fine resolution QuickBird satellite data, and land surface temperatures (Celsius), generated from ASTER imagery, over Phoenix, Arizona. Using daytime and nighttime temperatures in both winter and summer and all observation points $(\mathrm{n}=11,025)$, we develop linear, nonlinear and multiple regression models to explore the relationship. Conventional wisdom suggests that all urban features result in increased temperatures. Rather, our results show that a mass of buildings is not necessarily or holistically responsible for extreme heat in desert cities. It is the construction of other impervious dark surfaces (i.e., asphalt roads) associated with buildings that result in extreme heat. Moreover, our results suggest that buildings, especially commercial buildings with high albedo roofs, actually reduce temperatures. The addition of trees and shrubs, as opposed to grass, around buildings can further mitigate extreme heat by providing more cooling during the summer and increasing nighttime temperatures in the winter. In conclusion, the compositional design of and avoidance of dark impervious
\end{abstract}

S. W. Myint $(\bowtie) \cdot$ E. A. Wentz · A. J. Brazel

School of Geographical Sciences and Urban Planning, Arizona State University, Coor Hall, 5th Floor, 975 S. Myrtle Ave., Tempe, AZ 85287, USA

e-mail: soe.myint@asu.edu

D. A. Quattrochi

NASA, Earth Science Office, Marshall Spaceflight Center, Huntsville, AL 35812, USA materials in desert cities help mitigate extreme temperatures. It is important to note, however, that design choices that reduce extreme heat must be made within the broader context of tradeoffs and unintended consequences to ensure the sustainability of these cities.

Keywords Land surface temperature . Urban land cover · QuickBird · ASTER . High albedo roof $\cdot$ Dark surface $\cdot$ Phoenix

\section{Introduction}

The urban heat island (UHI) is the increase in minimum nighttime temperatures in an urban area compared to the surrounding non-urbanized region (Brazel et al. 2000). The UHI effect is caused by the increased heat storage capacity of urban materials (e.g., asphalt and concrete) and the anthropogenic heat discharge of human activities (Hucheon et al. 1967; Olfe and Lee 1971; Oke 1973). The UHI effect is being studied extensively to understand local climate patterns, human health, human activities, urban water, and energy use (Oke 1981, 1982; Huang et al. 1987; Sailor 1995; Spronken-Smith and Oke 1998; Carlson and Arthur 2000; Bonan 2002; Brabec et al. 2002; EPA 2003; Weng et al. 2004; Grossman-Clarke et al. 2005; Jenerette et al. 2007). Remotely sensed data provide an indirect approach to document the UHI and to correlate temperature to land cover (Carlson et al. 
1977; Quattrochi and Ridd 1994; Wilson et al. 2003; Weng et al. 2004; Hung et al. 2006; Xian 2006). The challenge with using remotely sensed data is that the classified data are typically generalized land cover categories and vegetation indices generated from lowresolution satellite sensors. This results in limited understanding in understanding the specific drivers of the UHI. In contrast, high-spatial resolution data (e.g., $<5 \mathrm{~m}$ pixel size) can extract detailed urban and suburban information from remotely sensed data (Jensen and Cowen 1999).

The goal of this study is to investigate the direct relation between detailed urban land-cover classes derived from QuickBird $2.4 \mathrm{~m}$ data and surface temperature from ASTER data for Phoenix, Arizona. We have selected two scenes per season to reflect daytime and nighttime differences in surface temperatures over a $178 \mathrm{~km}^{2}$ area to increase our understanding of the relationship between surface temperatures and urban materials. Using high-resolution imagery, we overcome previous challenges and understand more about the seasonal, diurnal, spatial and structural dynamics associated with the drivers and consequences of UHI. This enables us to better understand how anthropogenic features and natural landscapes influence urban warming in a rapidly urbanizing desert city.

\section{Remote sensing and UHI}

Temperature

Scientists quantify and monitor the UHI effect through a variety of direct and indirect methods, numerical modeling approaches and estimates based on empirical models. In situ measurements of air and surface temperature have traditionally been used to explore the surface energy balance and its impact on urban warming (Dousset 1989; Stoll and Brazel 1992; Lee 1993). However, these measures typically cover small geographic areas with a limited number of point observations instead of continuous records. Urban planners have suggested various strategies for addressing the UHI effect such as high albedo rooftops, reduction of impervious surfaces and increasing vegetation density (Gober et al. 2010) based on surface temperature observations. Details on mitigation measures, however, are difficult to come by over large geographic areas. Moreover, point measurements of air and surface temperatures may not represent warming over a sizable area in the context of the interactive nature of landscapes within complex urban settings.

Due to the small scale or estimated nature of in situ measurements, there is a good deal of uncertainty associated with the impact that other factors such as neighboring land covers, prevailing winds and wind direction have on urban energy balances. Thermal imagery has complemented in situ measurements by providing spatial richness across multiple temporal and spatial scales and in vertical directions. Hung et al. (2006) used land surface temperature obtained from Terra Moderate Resolution Imaging Spectroradiometer (MODIS) data to observe spatial patterns of UHI in 18 tropical and temperate Asian mega cities. Zhang et al. (1998) proposed a semi-theoretical method to estimate surface heat fluxes using Landsat TM satellite thermal-infrared data in conjunction with observational meteorological data and field measurements. Voogt and Oke (1997) and Voogt (2000) used direct and indirect thermal directional variation (thermal anisotropy) to estimate spatially weighted temperatures in both vertical and horizontal directions and show that the vertical structure and not just the surface area contribute to the urban sensible heat flux. Zhou et al. (2011) used land fragmentation indices to explore the spatial configuration of land cover types and surface temperatures in the Gwynns Falls watershed in Baltimore.

\section{Land cover characteristics}

To effectively mitigate the UHI effect, we need to quantify the specific drivers of urban heat retention within individual urban areas including the detailed composition and organization of the materials. Materials include varying amounts of plastic, metal, rubber, glass, cement, wood, shingle, sand, gravel, brick, stone, soil, vegetation and water (Sailor 1995; Arnfield 2003). The differential heating and cooling of these materials and their composition within urban structures alters the surface energy budget.

While data sources vary, overall findings show a strong relationship between impervious surfaces and higher surface temperatures as well as vegetated surfaces and cooler surface temperatures (Zhang et al. 1998; Hung et al. 2006). Dousset and Gourmelon 
(2003) found that business and industrial surfaces added significantly to the urban heat island effect in comparison to natural land covers, which tended to have a cooling effect. Buyantuyev and Wu (2010) found fractions of paved surface (as a nighttime indicator) and vegetation (as a daytime indicator) influence the spatio-temporal variation of surface temperatures. Wilson et al. (2003) explored differences in mean radiant surface temperatures and Normalized Difference Vegetation Index (NDVI) values generated from different types of zoning using Landsat Enhanced Thematic Mapper (ETM+) data, and reported that both variables were related to differences in zoning.

Other studies document UHI using more specific land use categories (e.g., residential, commercial, industrial). Li et al. (2011) explored UHI in Shanghai, China and reported that residential land-use areas with low- to middle-rise buildings and low vegetation cover have higher temperatures than areas with high-rise buildings and higher vegetation, concluding that urban landscape configuration influences UHI. However, land use commonly associated with human activities or economic functions generally contains many different types of land covers (Jensen 2004; Lillesand et al. 2008) that may have different levels or forms of influences on urban climate. For example, residential land use includes roads, houses, grass, shrubs, trees, bare soil, driveways, swimming pools, parking lots and sidewalks, each likely to be composed of different types of surface materials. This is true for other urban land uses such as commercial, industrial and recreational land uses as well. Voogt and Oke (2003) suggested that there is a need to use more fundamental surface descriptors rather than using qualitatively based land use data.

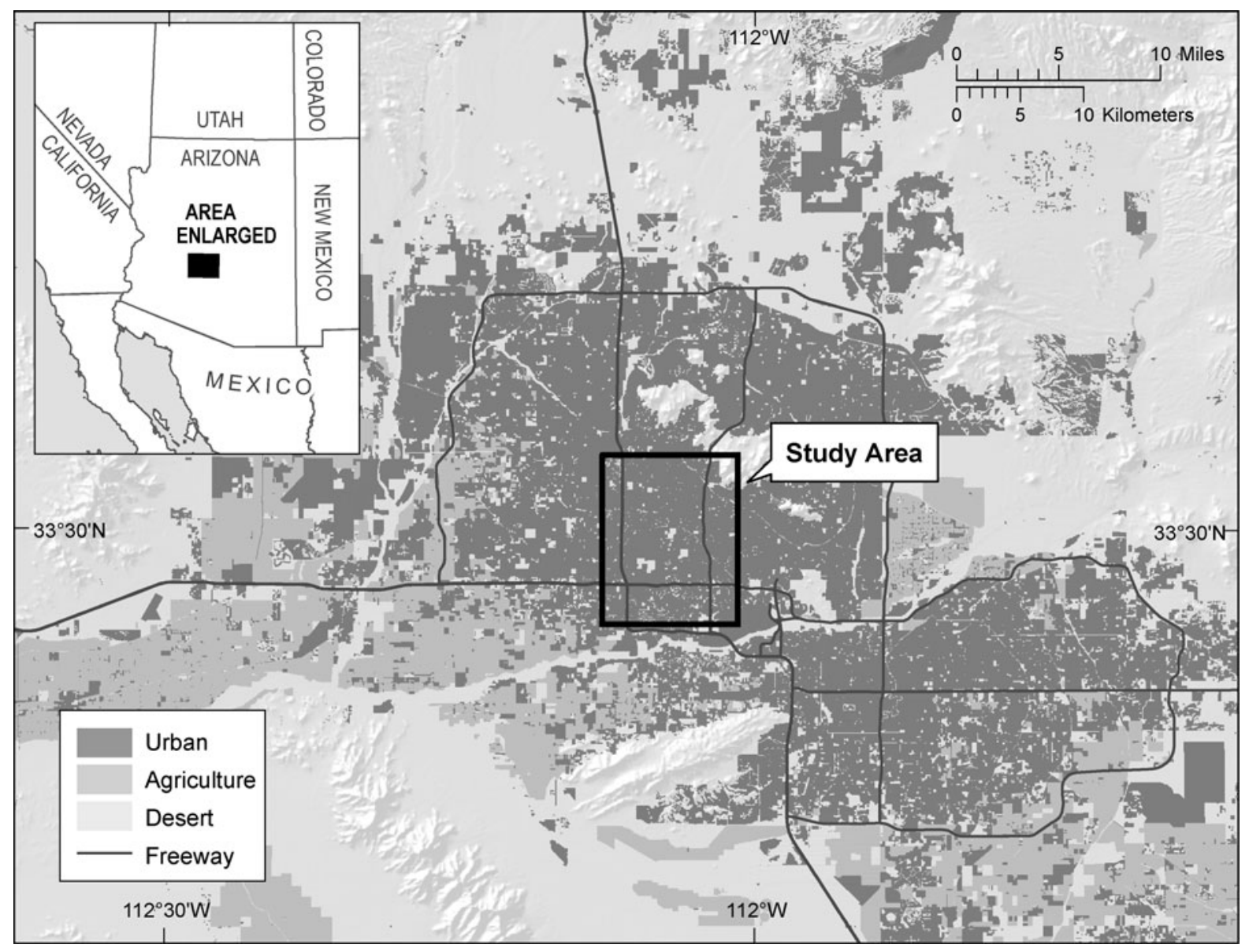

Fig. 1 Study area 
Refining the data and the land surface characteristics to enable more detailed analysis of the UHI effect continues to progress. Owen et al. (1998), in an attempt to analyze regional-scale climate impacts of urbanization, found that soil moisture from vegetation and its impacts on urban heat were poorly understood. They developed an empirical method to estimate the fractional cover and surface moisture availability from the surface temperature and NDVI that incorporates the influence of local land cover surrounding urbanized pixels. Studies such as these depend on either high-resolution data sources such as Quickbird or data processing approaches such as sub-pixel analysis to provide empirical information on the land surface characteristics. There are studies that have used subpixel analysis of medium to coarse-resolution imagery (e.g., Landsat; MODIS; NOAA-AVHRR) to quantify land cover fractions. Sub-pixel analysis can provide a relative abundance of surface material information, especially when dealing with medium to coarse spatial resolution satellite sensor images. There are limitations and uncertainties associated with sub-pixel analysis (Myint 2006) when attempting to identify a few key surface covers or endmembers that are not commonly identifiable in coarser resolution data (e.g., soil, impervious, vegetation).

\section{Study area}

The study area covers approximately $178 \mathrm{~km}^{2}$ of central Phoenix (Fig. 1; upper left longitude $112^{\circ} 7^{\prime} 45^{\prime \prime}$
Fig. 2 ASTER temperature (degree Celsius) images: a Nighttime temperature acquired on 22 August 2005; b Nighttime temperature acquired on 5 March 2007; c Daytime temperature acquired on 27 February 2007; d Daytime temperature acquired on 6 July 2005
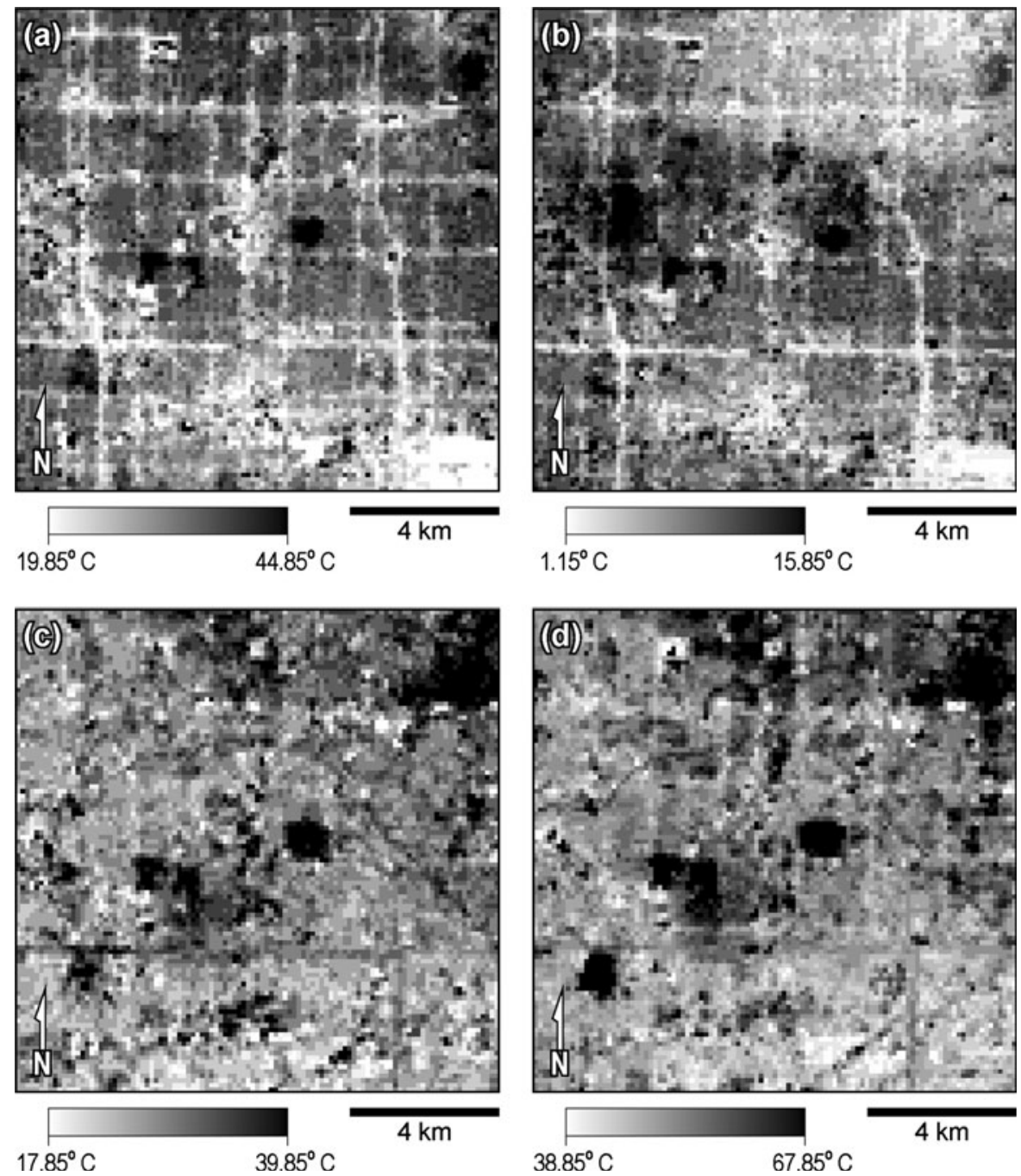
and latitude $33^{\circ} 33^{\prime} 15^{\prime \prime}$, lower right longitude $112^{\circ} 00^{\prime}$ $50^{\prime \prime}$ and latitude $33^{\circ} 26^{\prime} 2^{\prime \prime}$ ). The study area includes urban segments (commercial, industrial and residential) and undeveloped regions (grassland, unmanaged soil, desert landscape and open water), giving a diversity of urban land use and land cover classes. The Phoenix metropolitan area was selected because of its location in a desert environment that faces serious water consumption, energy use and heatrelated health problems, which are potentially linked to the UHI effect. The U.S. Census Bureau reports that the Phoenix metropolitan area is home to nearly 1.6 million people (U.S. Census Bureau 2012).

The temperature in Phoenix commonly exceeds 100 ${ }^{\circ} \mathrm{F}\left(38{ }^{\circ} \mathrm{C}\right)$ on an average of 110 days during the year, including most days from late May through early September, and reaches $110{ }^{\circ} \mathrm{F}\left(43{ }^{\circ} \mathrm{C}\right)$ or higher an average of 18 days. The average annual total rainfall measured at Phoenix Sky Harbor International Airport is about $210.82 \mathrm{~mm}$ (U.S. Department of Commerce 2010).

Fig. 3 Research design

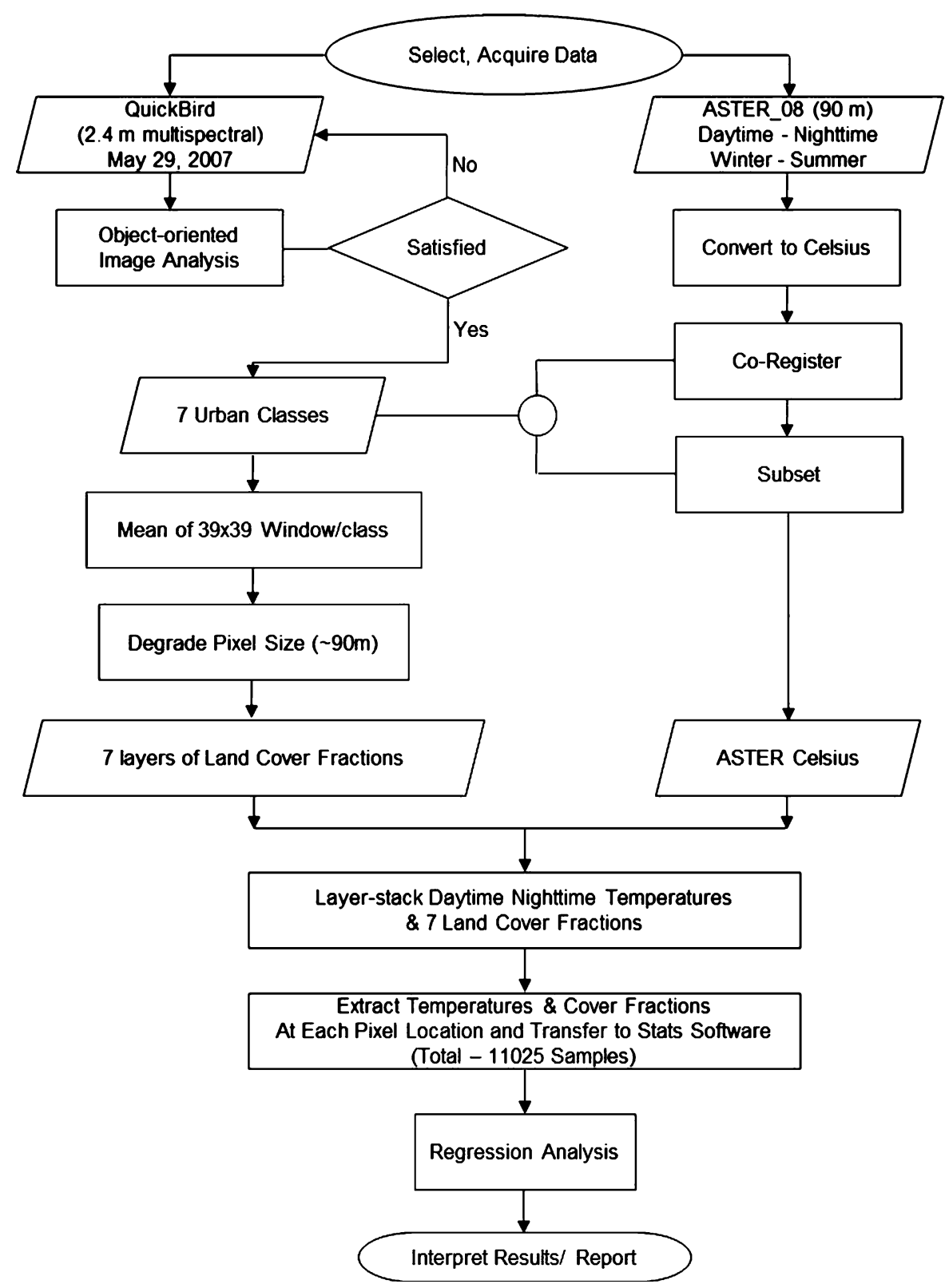




\section{Data sources}

The two data sources for this study are a QuickBird image to classify land cover and ASTER images that provide surface temperature during different seasons and different times of the day. The QuickBird image, dated 29 May 2007, has a $2.4 \mathrm{~m}$ spatial resolution with 4 channels: blue-B1 $(0.45-0.52 \mu \mathrm{m})$, green-B2 $(0.52-0.60 \mu \mathrm{m})$, red-B3 $(0.63-0.69 \mu \mathrm{m})$, and near infrared-B4 $(0.76-0.90 \mu \mathrm{m})$ and the radiometric resolution of the dataset is 16 bit. The image size is
5,339 rows $\times 5,570$ columns to cover the study area at this fine spatial resolution.

We also acquired Advanced Spaceborne Thermal Emission and Reflection Radiometer (ASTER) images from 6 July 2005, 22 August 2005, 27 February 2007, and 5 March 2007 to calculate land surface temperatures (Fig. 2a-d). Two scenes per season were used to reflect seasonal and daytime and nighttime differences in surface temperatures. ASTER provides advantages over other thermal sensors because it supplies more bands in the short-wave infrared portion of the
Fig. 4 a A subset of QuickBird image over the study area; b output map of the same area (a)

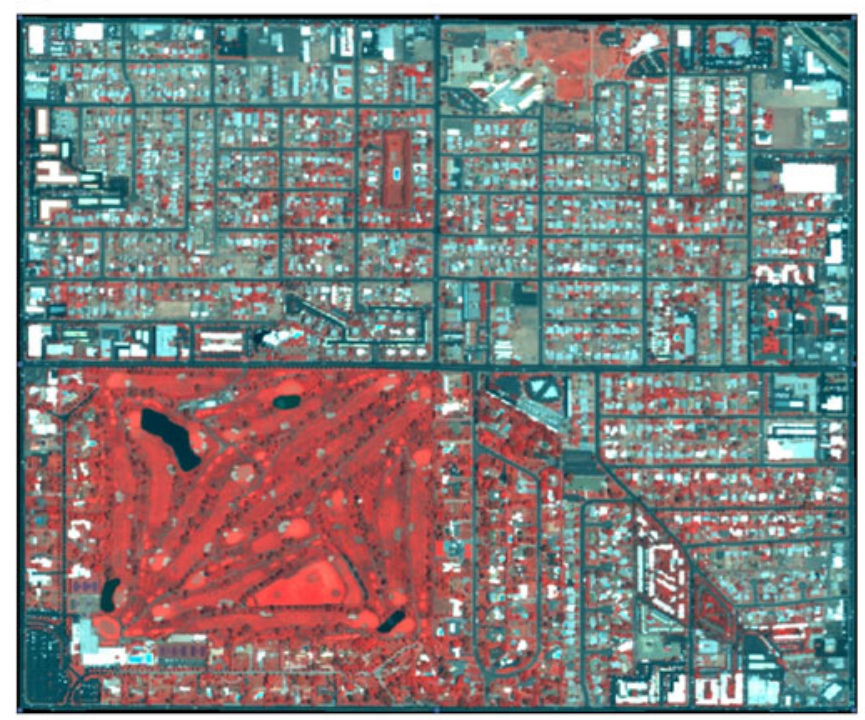

(b)

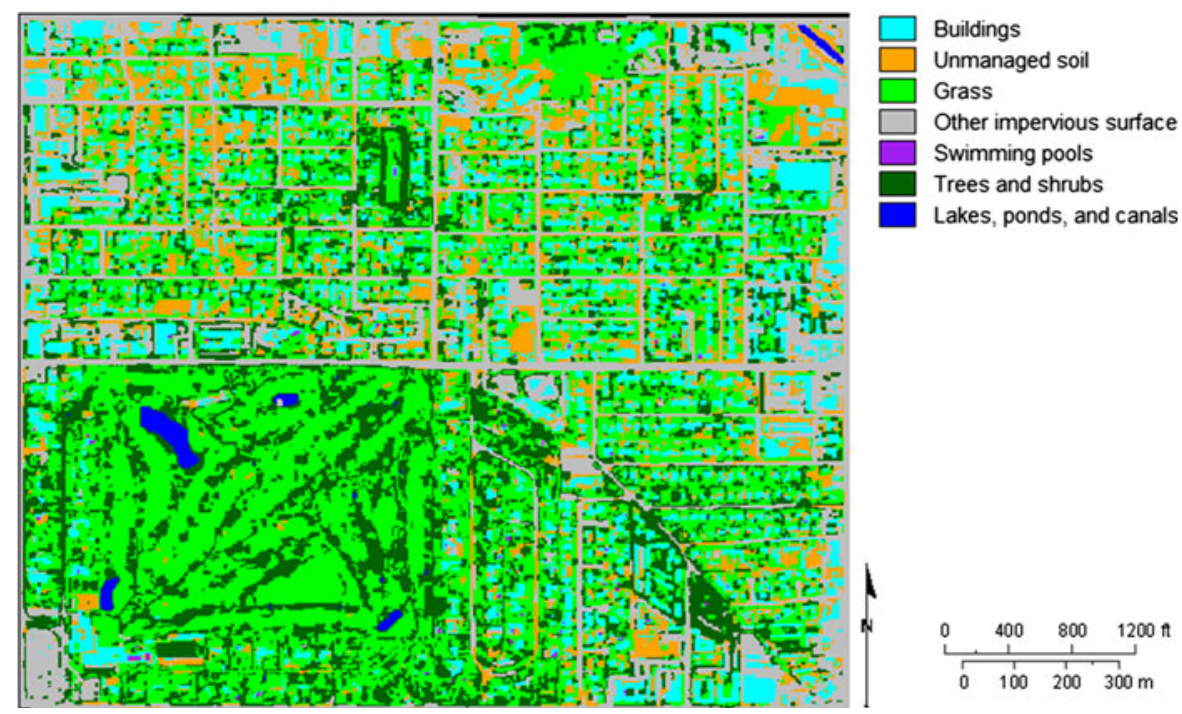


electromagnetic spectrum (SWIR) and thermal infrared (TIR) ( 6 bands in SWIR and 5 bands in TIR) while retaining adequate spatial resolution in the visible bands.

\section{Methods}

The research framework is illustrated in Fig. 3. Our basic methodology includes acquiring and classifying our remotely sensed images, spatially correlating the land cover fractions per surface temperature, and developing regression models with surface temperature as the dependent variable. The specifics of each step are described below.

Image classification and surface temperatures

We employed an object-oriented classification approach on the Quickbird image using decision rules and nearest neighbor classifier to extract detailed urban land cover classes with Definiens Developer 7.0 software (Benz et al. 2004; Walter 2004). A subset of QuickBird image over the study area and its output map are shown in Fig. 4. The original urban land cover categories identified included buildings, unmanaged soil, grass, other impervious surfaces (hereafter impervious), trees and shrubs, swimming pools and other water bodies (lakes, ponds and canals). These categories were selected because of ongoing studies of the urban energy budget that require these land cover classes (Grimmond and Oke 2002). The object-oriented classifier in our study achieved an overall accuracy of $90.4 \%$ (Myint et al. 2011), which is well above the minimum mapping accuracy of $85.0 \%$ required for most resource management applications (Anderson et al. 1976; Townshend 1981). For our study, we combined swimming pools (majority of water sources in the study area) and other water bodies (minimal water sources) to create a general water category reducing the total number of classes from seven to six.

Since there are two types of buildings (residential and commercial) in the study area, we split commercial and residential land use types in the study area using a heads-up digitizing option. We overlaid the land use type map onto the detailed urban land cover map to extract these two types of buildings. This allowed us to examine how each subclass of the building category influences surface temperatures

Per pixel surface temperature was calculated from ASTER's five thermal infrared channels using Planck's law and the emissivities from AST05 to scale the measured radiances after correction for atmospheric effects. The Kinetic $(\mathrm{K})$ temperature data

Table 1 Descriptive statistics and correlation matrix of the land cover categories

\begin{tabular}{|c|c|c|c|c|c|c|c|}
\hline Land cover & $\mathrm{N}$ & $\begin{array}{l}\text { Minimum } \\
\text { fractions }\end{array}$ & $\begin{array}{l}\text { Maximum } \\
\text { fractions }\end{array}$ & Mean & Median & Mode & SD \\
\hline Buildings & 11,025 & 0.00 & 0.754 & 0.194 & 0.190 & 0.200 & 0.077 \\
\hline Soil & 11,025 & 0.00 & 0.801 & 0.188 & 0.170 & 0.130 & 0.099 \\
\hline Grass & 11,025 & 0.00 & 0.952 & 0.220 & 0.210 & 0.020 & 0.149 \\
\hline Impervious & 11,025 & 0.00 & 0.953 & 0.269 & 0.250 & 0.120 & 0.151 \\
\hline Water & 11,025 & 0.00 & 0.052 & 0.002 & 0.000 & 0.000 & 0.003 \\
\hline \multirow[t]{3}{*}{ Trees } & 11,025 & 0.00 & 0.578 & 0.101 & 0.090 & 0.090 & 0.072 \\
\hline & \multicolumn{7}{|c|}{ Correlations $(\mathrm{N}=11,025)$} \\
\hline & Buildings & Soil & Grass & \multicolumn{2}{|c|}{ Impervious } & Water & Trees \\
\hline Buildings & 1 & & & & & & \\
\hline Soil & -.014 & 1 & & & & & \\
\hline Grass & $-.317 * *$ & $-.456 * *$ & 1 & & & & \\
\hline Impervious & $.110 * *$ & $.183 * *$ & $-.795 * *$ & 1 & & & \\
\hline Water & $-.079 * *$ & $-.093 * *$ & $.136 * *$ & & & 1 & \\
\hline Trees & $-.268 * *$ & $-.546 * *$ & $.719 * *$ & & & $.129 * *$ & 1 \\
\hline
\end{tabular}

** Correlation is significant at the 0.01 level 
Table 2 Descriptive statistics of surface temperatures $\left({ }^{\circ} \mathrm{C}\right)$

\begin{tabular}{|c|c|c|c|c|c|c|c|c|}
\hline Date & $\mathrm{N}$ & Time & Minimum $\left({ }^{\circ} \mathrm{C}\right)$ & Maximum $\left({ }^{\circ} \mathrm{C}\right)$ & Mean $\left({ }^{\circ} \mathrm{C}\right)$ & Median & Mode & SD \\
\hline 2-February-2007 & 11,025 & Daytime & 17.85 & 39.85 & 29.70 & 29.96 & 30.07 & 2.12 \\
\hline 6-July-2005 & 11,025 & Daytime & 38.85 & 67.85 & 55.83 & 56.41 & 56.96 & 3.42 \\
\hline 5-March-2007 & 11,025 & Nighttime & 1.15 & 15.85 & 10.44 & 10.41 & 9.96 & 2.02 \\
\hline 22-August-2005 & 11,025 & Nighttime & 19.85 & 44.85 & 31.56 & 31.41 & 30.74 & 2.20 \\
\hline
\end{tabular}

(i.e., ASTER08) in Hierarchical Data Format was used to convert temperatures into Celsius: $\mathrm{C}=\left(\mathrm{ASTER}_{-}\right.$ $08 * 0.1)^{*}(-273.15)$. The five thermal infrared channels of the ASTER instrument enable direct surface emissivity measurements, and hence, provide accurate temperature representation (JPL 2001). The absolute accuracy of ASTER08 ranges from 1 to $4 \mathrm{~K}$ and relative accuracy is $0.3 \mathrm{~K}$ (JPL 2001).

Image integration and regression analysis

To compare the land cover with the surface temperature, we registered both to a Universal Transverse Mercator (UTM) projection with WGS 84. In each $39 \times 39$ window $(2.4 \mathrm{~m} \times 39=93.6 \mathrm{~m})$, we
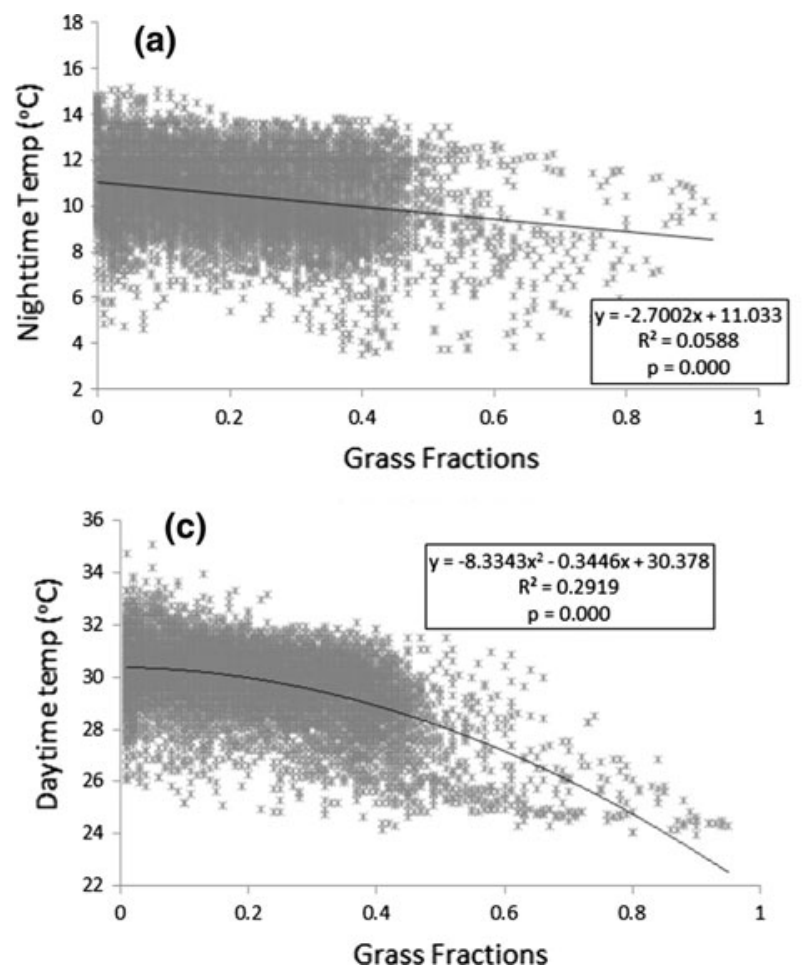

Fig. 5 Regression analysis between grass fractions and surface temperatures. a Grass fractions versus nighttime temperature $\left({ }^{\circ} \mathrm{C}\right)$ (5 March 2007); b Grass fractions versus nighttime calculated the fraction of each land cover, which represents the land cover fraction per ASTER pixel (90 $\mathrm{m}$ resolution). We also applied a mean local window $(3 \times 3)$ to the ASTER temperature data to minimize errors that might occur due to registration errors between the Quickbird and ASTER images.

We conducted thirty-two independent univariate regression models on $n=11,025$ observations (the total number of ASTER pixels in our study area) to quantify the relationship between surface temperature (dependent variable) and land cover fraction (independent variable). We compared four dependent variables (daytime winter, nighttime winter, daytime summer and nighttime summer) against the fraction of each land cover class (buildings, grass, unmanaged
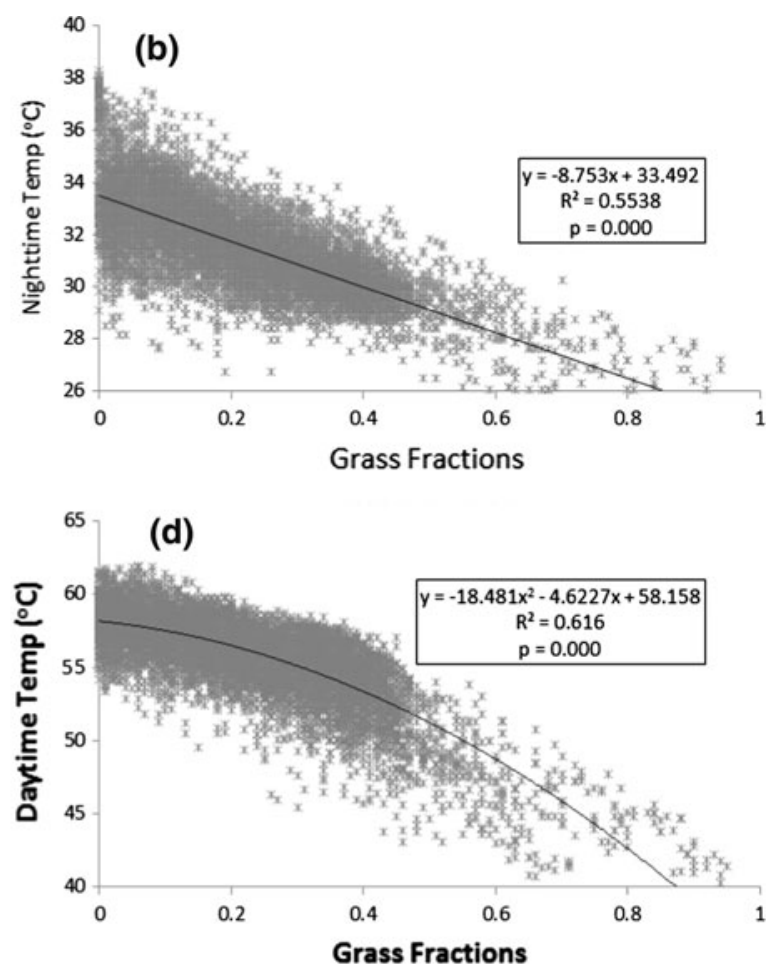

temperature $\left({ }^{\circ} \mathrm{C}\right)$ (22 August 2005); c Grass fractions versus daytime temperature $\left({ }^{\circ} \mathrm{C}\right)(27$ February 2007$)$; d Grass fractions versus daytime temperature $\left({ }^{\circ} \mathrm{C}\right)$ (6 July 2005$)$ 
soil, impervious, trees and water). We also explored the combined effects of the detailed land cover classes by developing multiple regression models. We used all of the selected classes as independent parameters.

\section{Results and discussions}

Table 1 shows that the water category has the lowest maximum (0.052) and lowest mean (0.002) since most water bodies in the study area are swimming pools and their area coverage is small in comparison to other land cover categories. The tree category is the second lowest coverage in the area with the mean value of 0.101 . The highest mean is given by the impervious class $(0.269)$ as it is the most widely covered category. However, mean values of most land cover classes are not greatly different from each other except for the water category. It should also be noted that most categories are negatively correlated (Table 1).
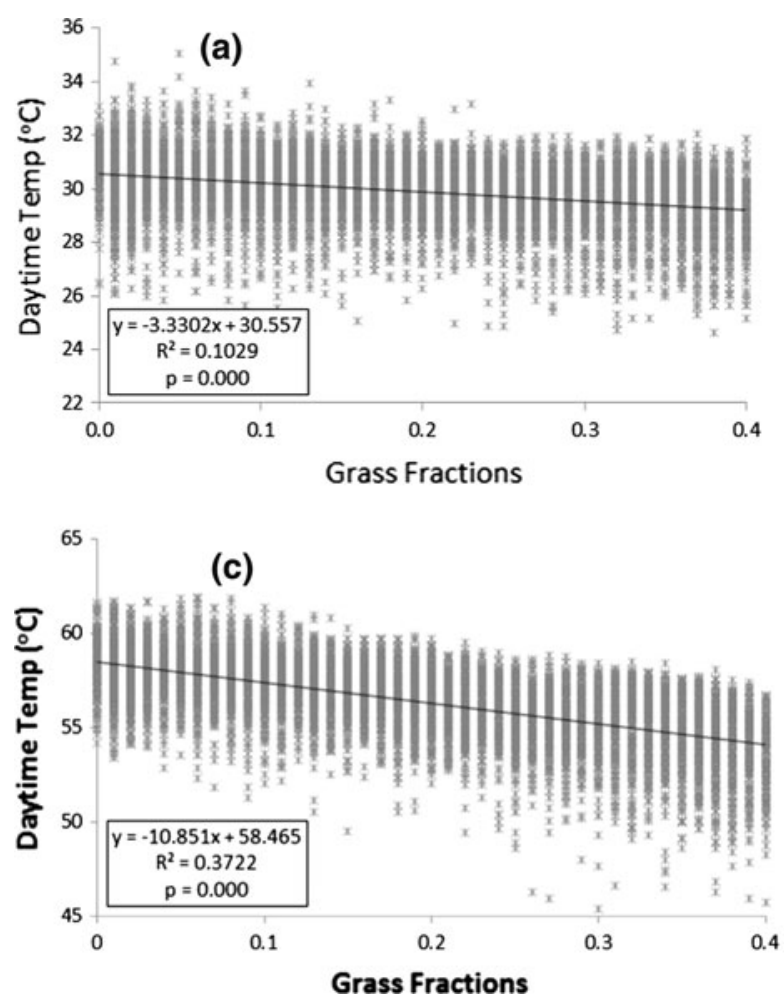

Fig. 6 Regression analysis between grass fractions (x axis) and surface temperatures (y axis). a Grass fractions (0-0.4) versus daytime temperature $\left({ }^{\circ} \mathrm{C}\right)(27$ February 2007); b Grass fractions (0.4-1) versus daytime temperature $\left({ }^{\circ} \mathrm{C}\right)$ (27 February 2007);
Grass and impervious have the highest deviations from their mean values $(0.149$ and 0.151$)$, are negatively correlated, and have the highest correlation $(-0.795)$. Other strongly correlated classes include grass versus trees (0.719), impervious versus trees $(-0.597)$, soil versus trees $(-0.547)$ and grass versus soil $(-0.456)$. Buildings are inversely correlated with grass $(-0.318)$ and trees $(-0.269)$. The summer day and night images yielded mean temperatures of 55.83 and $31.56{ }^{\circ} \mathrm{C}$, respectively whereas the winter day and night images showed greatly lower mean temperatures of 29.70 and $10.44{ }^{\circ} \mathrm{C}$, respectively (Table 2). However, standard deviation (SD) values of the surface temperatures are not significantly different among the different dates.

Figure 5a shows that grass fractions do not have a strong impact on nighttime surface temperatures during the winter. However, there was a strong negative linear relation between grass fractions and nighttime temperature in the summer (Fig. 5b). We
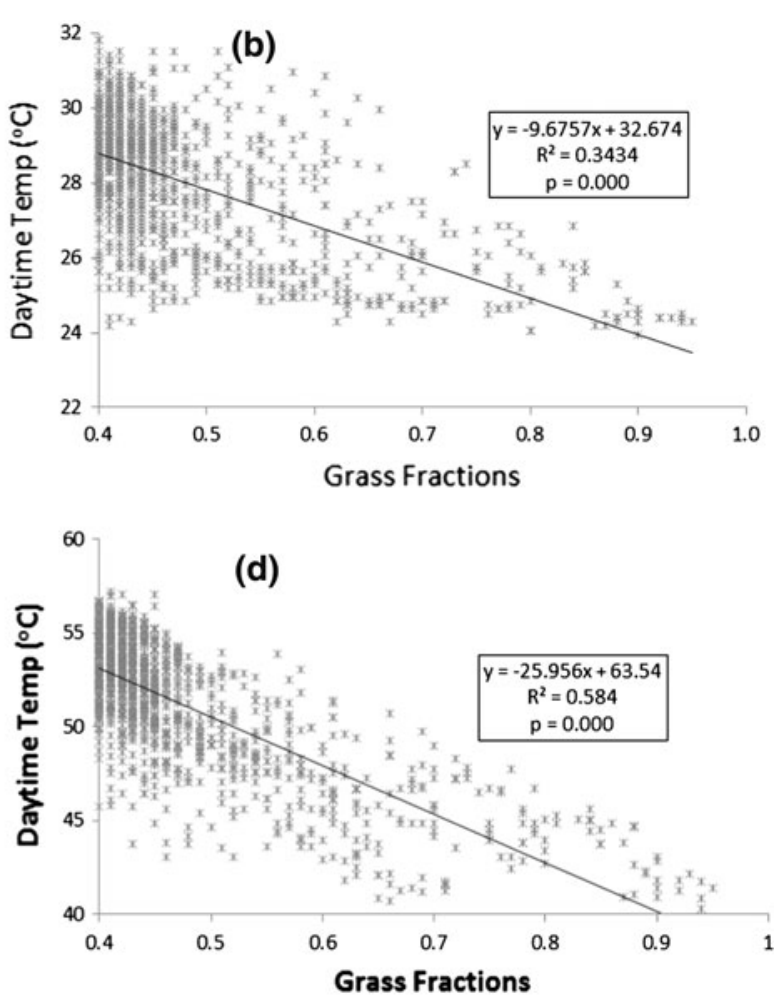

c Grass fractions (0-0.4) versus daytime temperature $\left({ }^{\circ} \mathrm{C}\right)$ (6 July 2005); d Grass fractions (0.4-1) versus daytime temperature $\left({ }^{\circ} \mathrm{C}\right)(6$ July 2005$)$ 
observed that grassy surfaces effectively lower nighttime temperatures as temperature increases in the summer. However, there are non-linear relationships between grass fractions and daytime surface temperatures both in winter and summer. It can be observed from Fig. 5c, d that regression slopes are gentle for grass percent ranging from about 0 to $40 \%$ and get significantly steeper with increasing grass fraction values above $40 \%$.

To observe this trend more effectively we split grass surface percent into two groups $(0-40 \%$ and 40-100\%) and observed their relationships with surface temperatures. The relationships are presented in Fig. 6a-d. Figure $6 a$ indicates that there was a small relationship with a gentle regression slope between grass fractions and daytime surface temperatures in the winter. There is a similar relationship in the summer. This shows that grass surface lower than $40 \%$ are not effective in lowering daytime temperatures both in the winter and summer. In contrast, grass surfaces higher than $40 \%$ have influence on lowering surface temperatures both in the winter and summer (Fig. 6b, d).
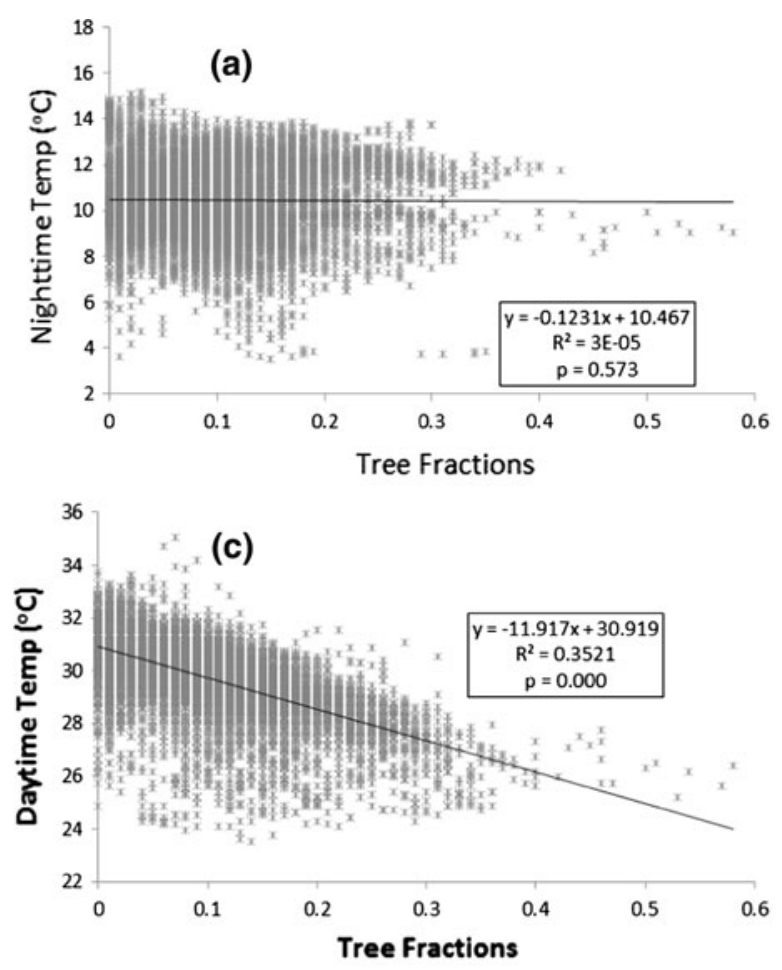

Fig. 7 Regression analysis between tree fractions (x axis) and surface temperatures (y axis). a Tree fractions versus nighttime temperature $\left({ }^{\circ} \mathrm{C}\right)$ (5 March 2007$)$; b Tree fractions versus
We discovered that there is no relationship between trees and nighttime surface temperatures during winter (Fig. 7a). However, trees are negatively correlated with winter daytime temperatures (Fig. 7c). The same negative correlation is observed for both daytime and nighttime temperatures during summer (Fig. 7b, d). It is important to note that the regression slopes are steeper for tree fractions than grass fractions. This implies that trees can lower surface temperatures more effectively than grassy areas in desert urban environments. The relationships between trees and temperatures as we observed in the study were based on very low tree cover percent mostly ranging between 0 and $30 \%$ whereas there are many areas or pixels containing grass fractions higher than $40 \%$ (e.g., grass fractions in golf courses). The regression models suggest that $20 \%$ increase in tree area coverage in a neighborhood can cool nighttime surface temperatures by -0.02 to $-2.71{ }^{\circ} \mathrm{C}$ and daytime surface temperatures by -2.38 to $-5.74{ }^{\circ} \mathrm{C}$ in winter and summer respectively. However, grass is not as effective as tress and can cool only about half the surface temperatures that trees can lower.
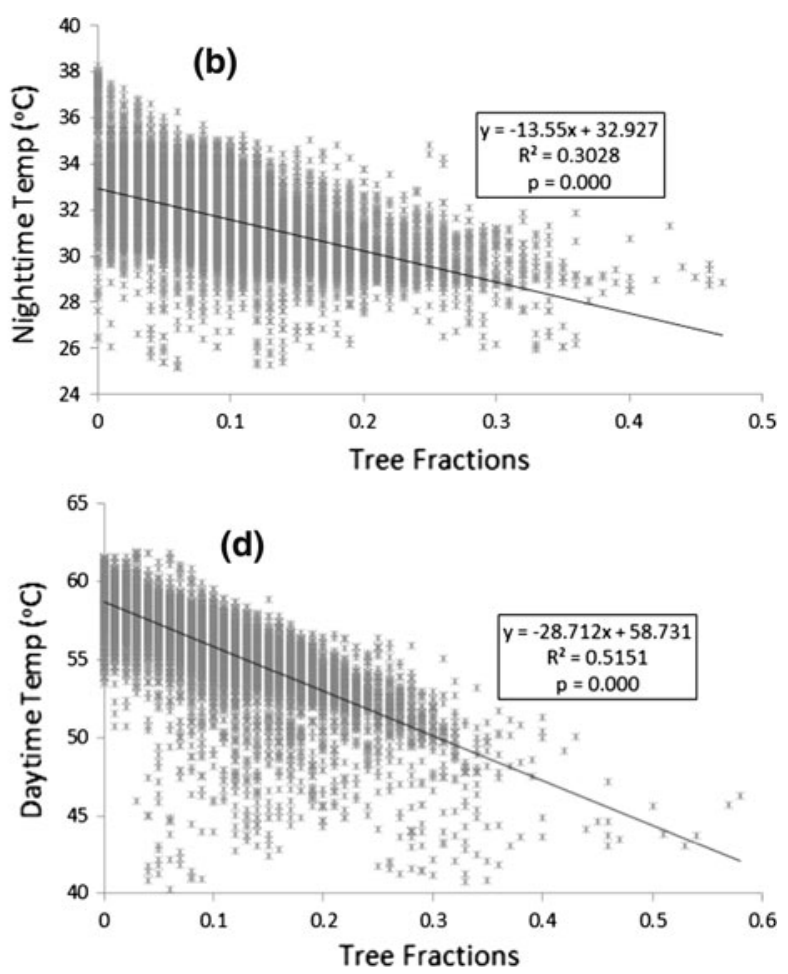

nighttime temperature $\left({ }^{\circ} \mathrm{C}\right)$ (22 August 2005); $\mathbf{c}$ Tree fractions versus daytime temperature $\left({ }^{\circ} \mathrm{C}\right)(27$ February 2007); d Tree fractions versus daytime temperature $\left({ }^{\circ} \mathrm{C}\right)$ (6 July 2005) 
There is no relationship between water fractions and nighttime temperatures that are statistically significant regardless of the season (Fig. 8a, b). The relationships with daytime temperatures were very low at 0.01 significance level (Fig. 8c, d) since most water was swimming pools. Hereafter, water may be referred to as swimming pools. There may not be any swimming pool or their fraction values could be close to zero at $90 \times 90 \mathrm{~m}$ spatial resolution in some cases. Therefore, we conclude that swimming pools do not have any considerable impact on nighttime temperatures nor do they effectively lower thermal energy during the day in a desert environment. This finding is different from what was reported in Guhathakurta and Gober (2010).

Contrary to a common perception as well, buildings are negatively correlated to nighttime surface temperatures during winter (Fig. 9a). Moreover, there is no relation between nighttime surface temperatures in the summer and building fractions (Fig. 9b). We discovered that buildings lower the nighttime temperature in
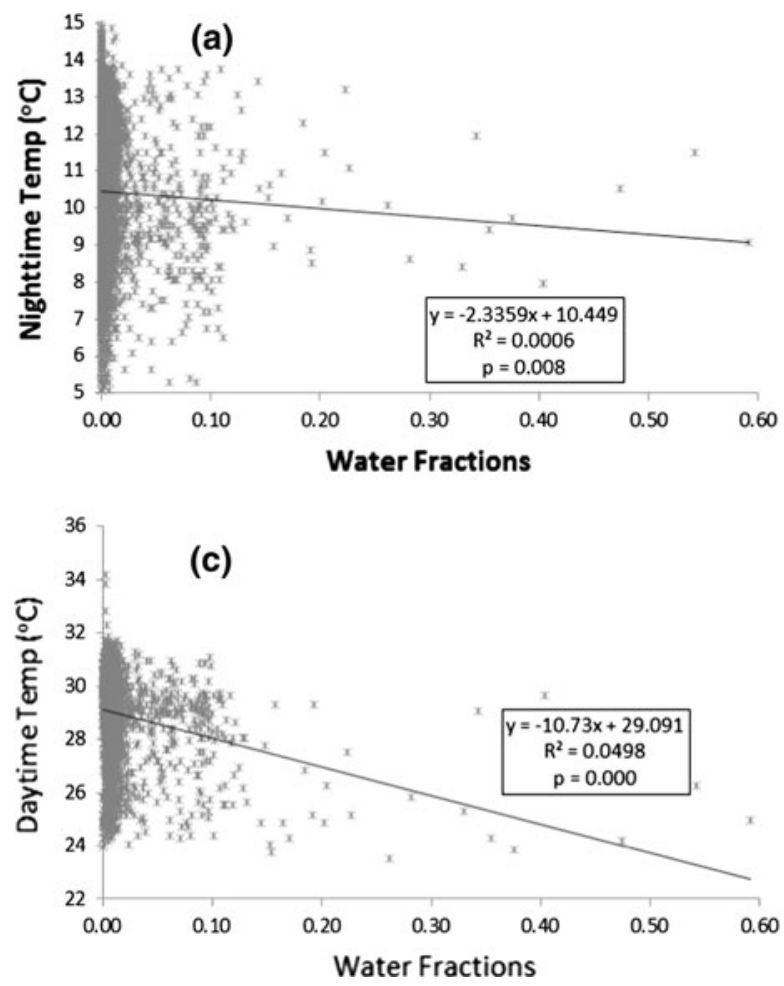

Fig. 8 Regression analysis between water fractions (x axis) and surface temperatures (y axis). a Water fractions versus nighttime temperature $\left({ }^{\circ} \mathrm{C}\right)$ (5 March 2007); b Water fractions versus the winter and do not have any impact on the nighttime temperature in the summer. It was also found that the relations between building fractions and daytime temperatures were low, and the slopes of regression lines were small (Fig. 9c, d). This implies that building fractions do not have a significant impact on daytime temperatures in both winter and summer.

From Fig. 9a-d, we observe that buildings function as environmentally friendly materials to lower surface temperatures at night and have a minimal impact on urban warming. This finding contradicts the way we traditionally have been thinking. The phenomenon may be due to a number of factors. First, most rooftops and building walls in our study area are composed of bright materials leading to high reflectance and lower heat retention. Artificial cooling or indoor cooling facility in buildings especially in a desert environment may also play a factor in influencing the urban temperature. Furthermore, buildings create surface roughness that may interact with surrounding materials such as trees and grass. Finally, buildings provide
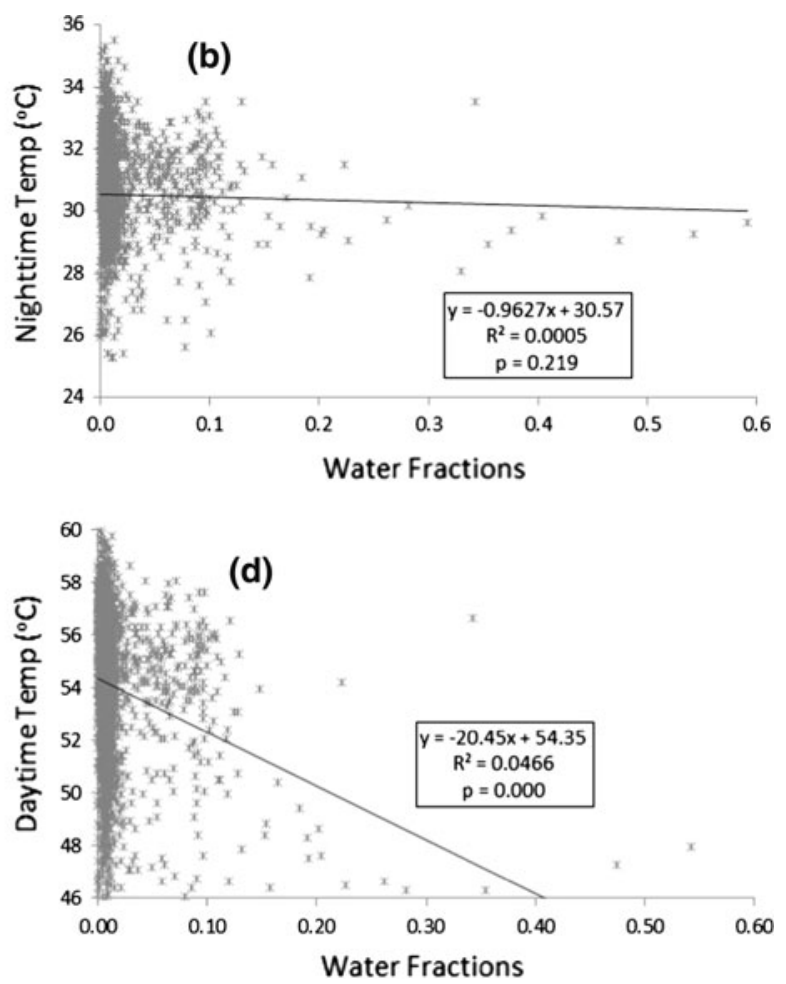

nighttime temperature $\left({ }^{\circ} \mathrm{C}\right)(22$ August 2005); c Water fractions versus daytime temperature $\left({ }^{\circ} \mathrm{C}\right)(27$ February 2007); d Water fractions versus daytime temperature $\left({ }^{\circ} \mathrm{C}\right)$ (6 July 2005) 

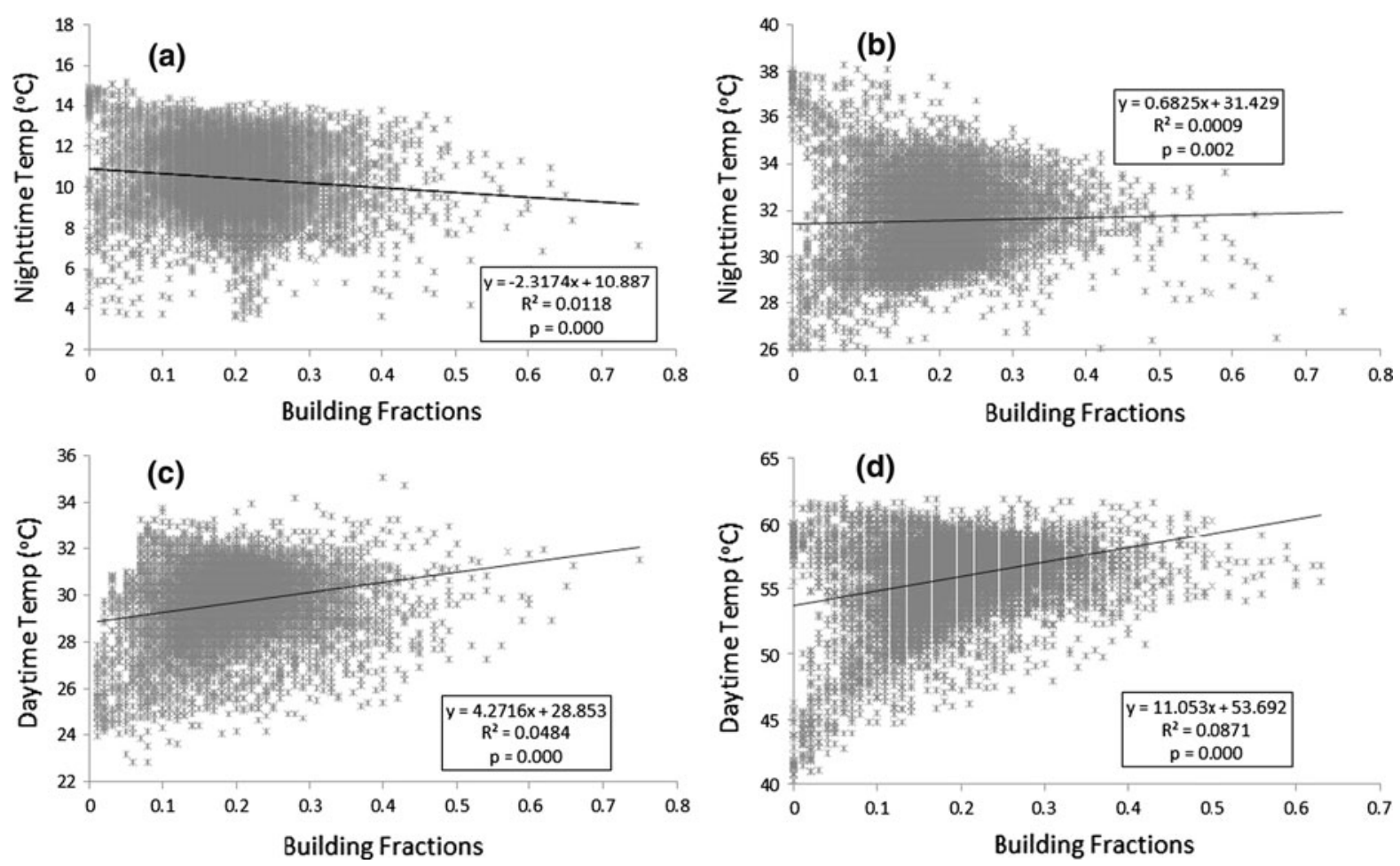

Fig. 9 Regression analysis between building fractions (x axis) and surface temperatures (y axis). a Building fractions versus nighttime temperature $\left({ }^{\circ} \mathrm{C}\right)$ (5 March 2007); b Building fractions versus nighttime temperature $\left({ }^{\circ} \mathrm{C}\right)$ (22 August 2005);

shade almost the entire day except around noon thereby providing a cooling effect and acting somewhat like vegetation. Since we observed a pattern that shows two different correlation trends between buildings and surface temperatures in Fig. 10b-d (i.e., 32 ${ }^{\circ} \mathrm{C}$ for Fig. $10 \mathrm{~b}, 30{ }^{\circ} \mathrm{C}$ for Fig. $10 \mathrm{c}$, and $55^{\circ} \mathrm{C}$ for Fig. 10d), we decided to examine which subtypes of the buildings fall into the two groups, and explore their contributions to surface temperature. To achieve this, we digitized residential and commercial land use types to split residential and commercial buildings. Many UHI studies showed the relation between impervious surfaces or paved areas mostly as fractions at sub-pixel level. Since buildings, swimming pools and other impervious surface (e.g., roads, parking lots, driveways, sidewalks) are man-made and do not allow water to infiltrate to the soil, they are categorized together as impervious. It is not possible to examine how different man-made features influence urban surface temperatures when dealing with fractions of

c Building fractions versus daytime temperature $\left({ }^{\circ} \mathrm{C}\right)(27$ February 2007); d Building fractions versus daytime temperature $\left({ }^{\circ} \mathrm{C}\right)$ (6 July 2005)

impervious as a whole (Myint et al. 2010). Therefore we not only explored buildings, swimming pools and other impervious separately but also examined different types of buildings independently.

From Fig. 10a-d and Table 3 it can be observed that one of the most significant correlations for urban land use types is the nighttime summer commercial area of roofs. There is a cooling of commercial areas $8{ }^{\circ} \mathrm{C}$ by increasing commercial buildings from a low percent of $10 \%$ upwards of $60 \%$. Specifically, commercial roofs have negative relationships with surface temperatures at 0.01 level implying that they lower surface temperatures especially when dealing with summer nighttime temperatures (statistically significant $r$ of $-0.312,-0.165,-0.402$, and -0.201 ). Since most commercial roofs in the study area have lightcolored reflective roofs and building fraction is inversely correlated to impervious surface areas $(r=-0.270)$ (Table 4), which more readily store heat for release at night, the radiating roof level areas would be cooling 

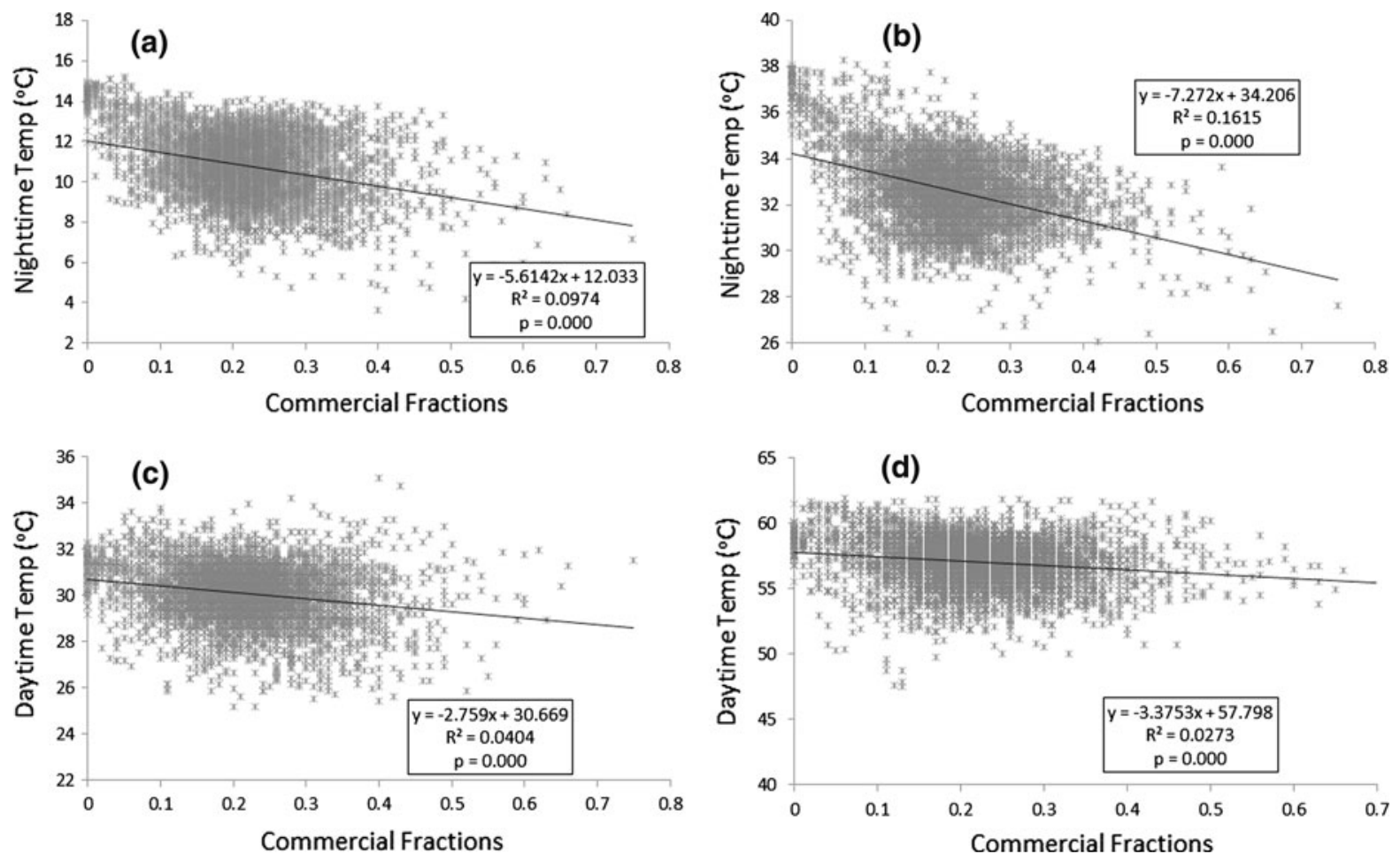

Fig. 10 Regression analysis between commercial building fractions (x axis) and surface temperatures (y axis). a Commercial building fractions versus nighttime temperature $\left({ }^{\circ} \mathrm{C}\right)$ (5 March 2007); b Commercial building fractions versus

nighttime temperature $\left({ }^{\circ} \mathrm{C}\right.$ ) (22 August 2005); c Commercial building fractions versus daytime temperature $\left({ }^{\circ} \mathrm{C}\right)(27$ February 2007); d Commercial building fractions versus daytime temperature $\left({ }^{\circ} \mathrm{C}\right)$ (6 July 2005 )

Table 3 Correlation matrix of buildings (i.e., commercial, residential) and surface temperatures

\begin{tabular}{|c|c|c|c|c|c|}
\hline \multirow[t]{2}{*}{$(\mathrm{N}=5,071)$} & \multicolumn{5}{|l|}{ Correlations } \\
\hline & Commercial & $\begin{array}{l}5 \text { March } 2007 \\
\text { (ntemp) }\end{array}$ & $\begin{array}{l}6 \text { July } 2005 \\
\text { (dtemp) }\end{array}$ & $\begin{array}{l}22 \text { August } 2005 \\
\text { (ntemp) }\end{array}$ & $\begin{array}{l}27 \text { February } 2007 \\
\text { (dtemp) }\end{array}$ \\
\hline Commercial & 1 & & & & \\
\hline 5 March 2007 (ntemp) & $-.312 * *$ & 1 & & & \\
\hline 6 July 2005 (dtemp) & $-.165 * *$ & $.089 * *$ & 1 & & \\
\hline 22 August 2005 (ntemp) & $-.402 * *$ & $.523 * *$ & $.421 * *$ & 1 & \\
\hline 27 February 2007 (dtemp) & $-.201 * *$ & $.053 * *$ & $.714 * *$ & $.244 * *$ & 1 \\
\hline$(\mathrm{N}=55,954)$ & Residential & $\begin{array}{l}5 \text { March } \\
2007 \\
\text { (ntemp) }\end{array}$ & $\begin{array}{l}6 \text { July } \\
2005 \\
\text { (dtemp) }\end{array}$ & $\begin{array}{l}22 \text { August } \\
2005 \\
\text { (ntemp) }\end{array}$ & $\begin{array}{l}27 \text { February } \\
2007 \\
\text { (dtemp) }\end{array}$ \\
\hline Residential & 1 & & & & \\
\hline 5 March 2007 (ntemp) & -.020 & 1 & & & \\
\hline 6 July 2005 (dtemp) & $.517 * *$ & $-.069 * *$ & 1 & & \\
\hline 22 August 2005 (ntemp) & $.214 * *$ & $.196 * *$ & $.637 * *$ & 1 & \\
\hline 27 February 2007 (dtemp) & $.415^{* *}$ & $-.214 * *$ & $.856 * *$ & $.493 * *$ & 1 \\
\hline
\end{tabular}

** Correlation is significant at the 0.01 level 
Table 4 Correlation matrix of buildings (i.e., commercial, residential) and other selected land cover categories

\begin{tabular}{lllll}
\hline \multicolumn{5}{c}{ Correlations $(5,071)$} \\
\cline { 2 - 5 } & Commercial & Impervious & Trees & Grass \\
\hline Commercial & 1 & & & \\
Impervious & $-.270 * *$ & 1 & & \\
Trees & $-.035^{*}$ & $-.460 * *$ & 1 & \\
Grass & $-.082 * *$ & $-.650 * *$ & $.737 * *$ & 1 \\
\hline & Correlations & $(5,954)$ & & \\
\cline { 2 - 5 } & Residential & Impervious & Trees & Grass \\
\hline Residential & 1 & & & \\
Impervious & $.182 * *$ & 1 & & \\
Trees & $-.294 * *$ & $-.467 * *$ & 1 & \\
Grass & $-.297 *$ & $-.708 * *$ & $.571 * *$ & 1 \\
\hline
\end{tabular}

* Correlation is significant at the 0.05 level

** Correlation is significant at the 0.01 level
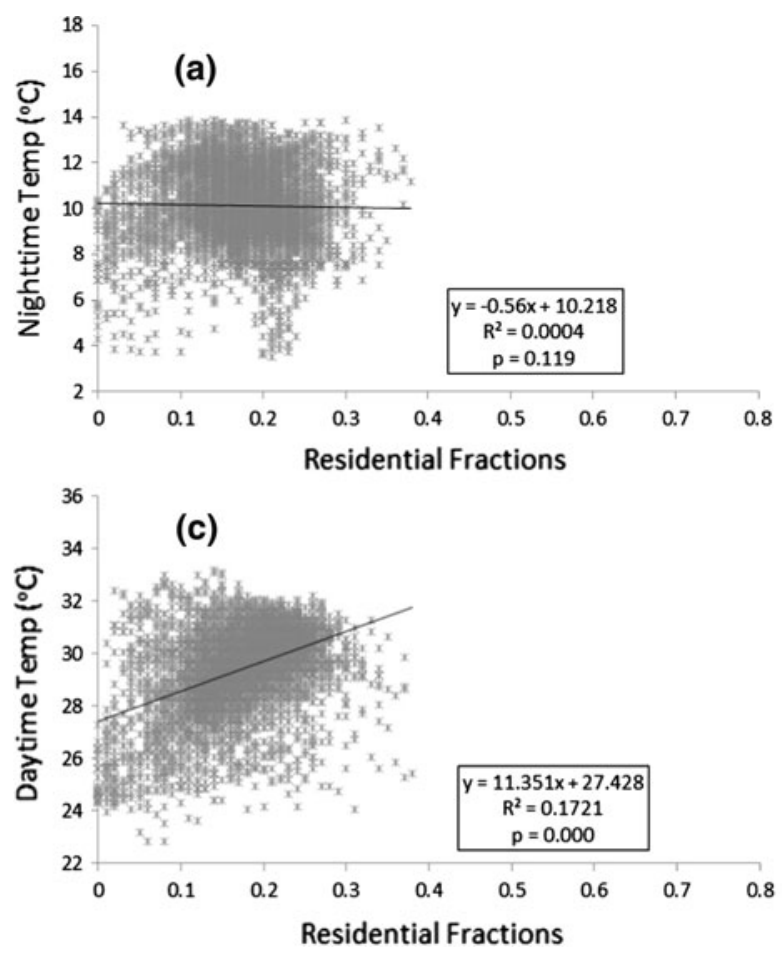

Fig. 11 Regression analysis between residential building fractions (x axis) and surface temperatures (y axis). a Residential building fractions versus nighttime temperature $\left({ }^{\circ} \mathrm{C}\right)(5 \mathrm{March}$ 2007); b Residential building fractions versus nighttime more effectively than the canyons between buildings composed mostly of parking areas and impervious surfaces. The cooling of some commercial areas increases with the percent (from a low of $10 \%$ to upwards of $70 \%$ ) of commercial buildings in the area. Thus, higher building fractions with high albedo roofs within the commercial areas lead to cooler overall surface temperatures compared to lower commercial building fraction areas with more asphalt and other dark, impervious surfaces. There also appears to be a slightly low negative correlation between more commercial building fraction and surface temperatures during the daytime in summer. Within commercial areas the largest factor may be that more impervious surfaces lead to less vegetation (trees $\mathrm{r}=-0.460$; grass $\mathrm{r}=-0.650$ ) (Table 4). More commercial buildings also create less impervious surface fractions. So a low-density, lowvegetation commercial area would be hotter due to heat absorption of impervious surfaces; whereas, a higher
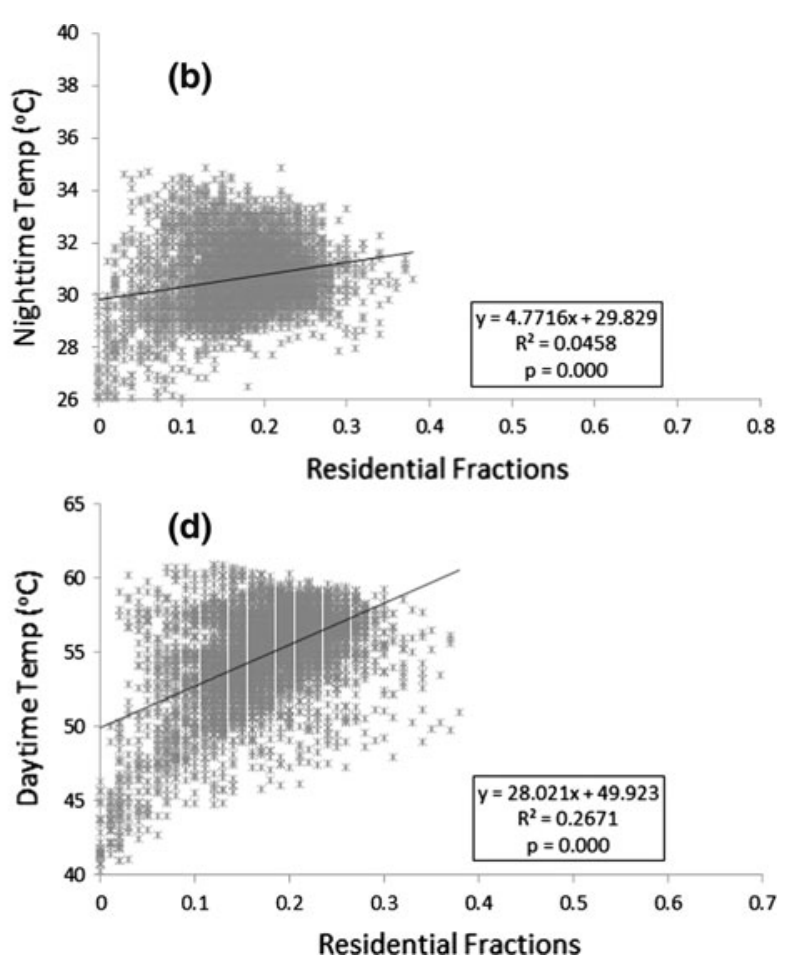

temperature $\left({ }^{\circ} \mathrm{C}\right)$ (22 August 2005); c Residential building fractions versus daytime temperature $\left({ }^{\circ} \mathrm{C}\right)(27$ February 2007); d Residential building fractions versus daytime temperature $\left({ }^{\circ} \mathrm{C}\right)$ (6 July 2005) 

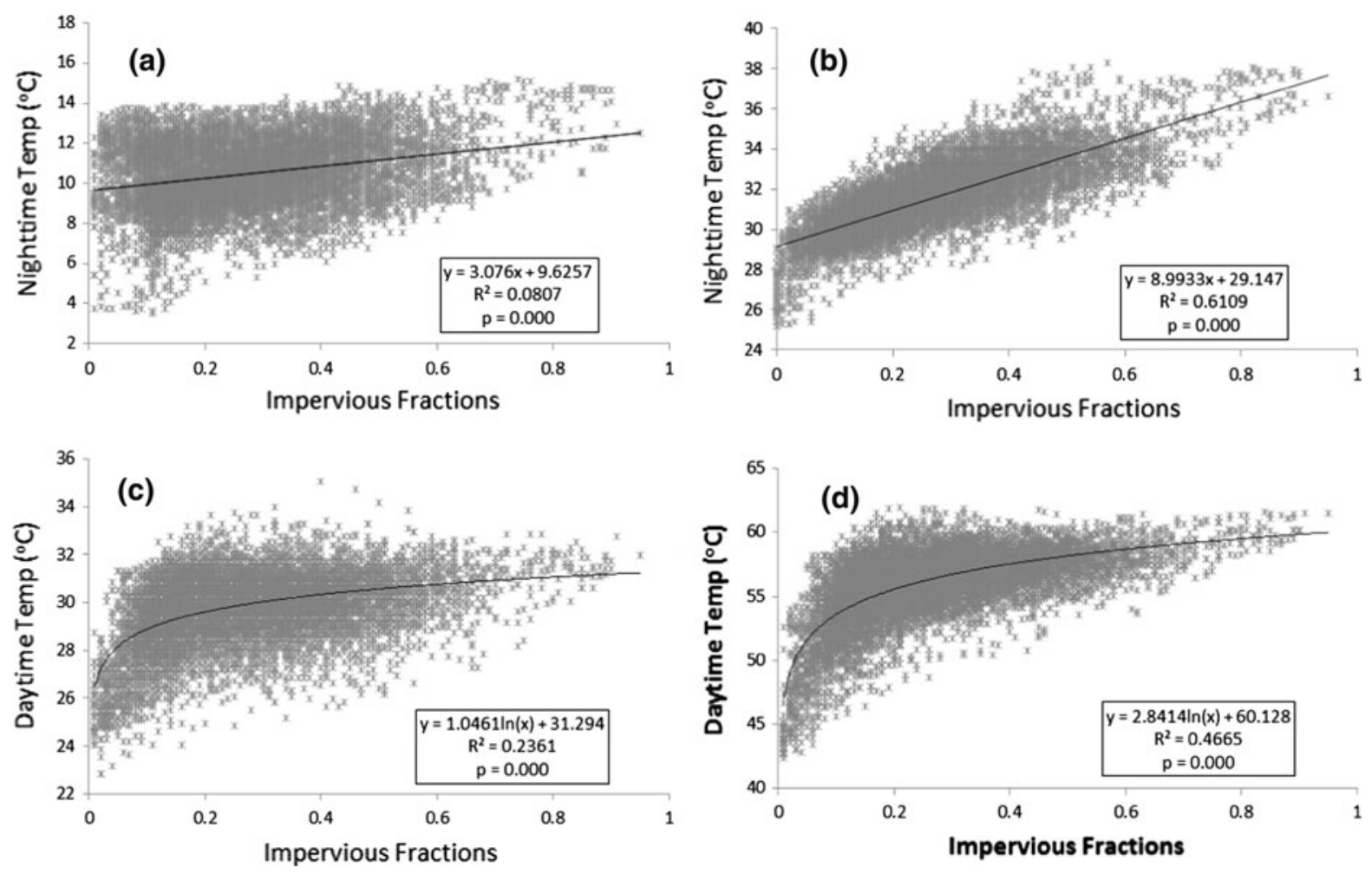

Fig. 12 Regression analysis between impervious fractions ( $\mathrm{x}$ axis) and surface temperatures (y axis). a Impervious fractions versus nighttime temperature $\left({ }^{\circ} \mathrm{C}\right)$ (5 March 2007); b Impervious fractions versus nighttime temperature $\left({ }^{\circ} \mathrm{C}\right)(22$

building fraction reduces the impervious effect and therefore the need for vegetation.

Unlike the findings for commercial buildings, residential buildings showed positive relationships with surface temperatures (Fig. 11b-d; Table 3) except nighttime temperatures in the summer. The highest coefficient of determination is summer daytime residential situations of more houses creating more roof area at the expense of available trees and grass which would act to cool. This is evidenced by an inverse correlation of residential building fraction and tree and grass fraction ( $\mathrm{r}$ of -0.294 and -0.297 for trees and grass, respectively in Table 4). Furthermore, residential houses are typically one- or two-story buildings, thus they do not provide a significant cooling effect for nearby areas and other houses. As we observed a weak inverse relationship between residential buildings and winter nighttime temperatures (Fig. 11a; Table 3), we can conclude that residential buildings have no impact on or ineffectively lower surface temperatures in winter.

August 2005); c Impervious fractions versus daytime temperature $\left({ }^{\circ} \mathrm{C}\right)$ (27 February 2007); d Impervious fractions versus daytime temperature $\left({ }^{\circ} \mathrm{C}\right)$ (6 July 2005)

In contrast to the above anthropogenic features, impervious surfaces (e.g., roads, parking lots, driveways, sidewalks) augment nighttime surface temperatures significantly, regardless of whether they are observed in winter or summer (Fig. 12a-d). Fractions of impervious surface have a non-linear relation and strong impact on daytime surface temperatures as well. In general, coefficients of determination $\left(\mathrm{R}^{2}\right)$ values of all observations for these surfaces were significantly higher than buildings. It can be observed from Fig. 12c, d that fractions of impervious surfaces ranging from 0 to about 0.4 can increase daytime temperatures at increasingly high rates. The rate of change of temperatures decreases as fractions increase after about 0.4. This is because almost all impervious surfaces (roads and parking lots) in the City of Phoenix are made of asphalt (dark surface).

There have also been several studies that demonstrated a linear relationship between impervious surfaces as a whole (commercial buildings, residential buildings, swimming pools, and other impervious 

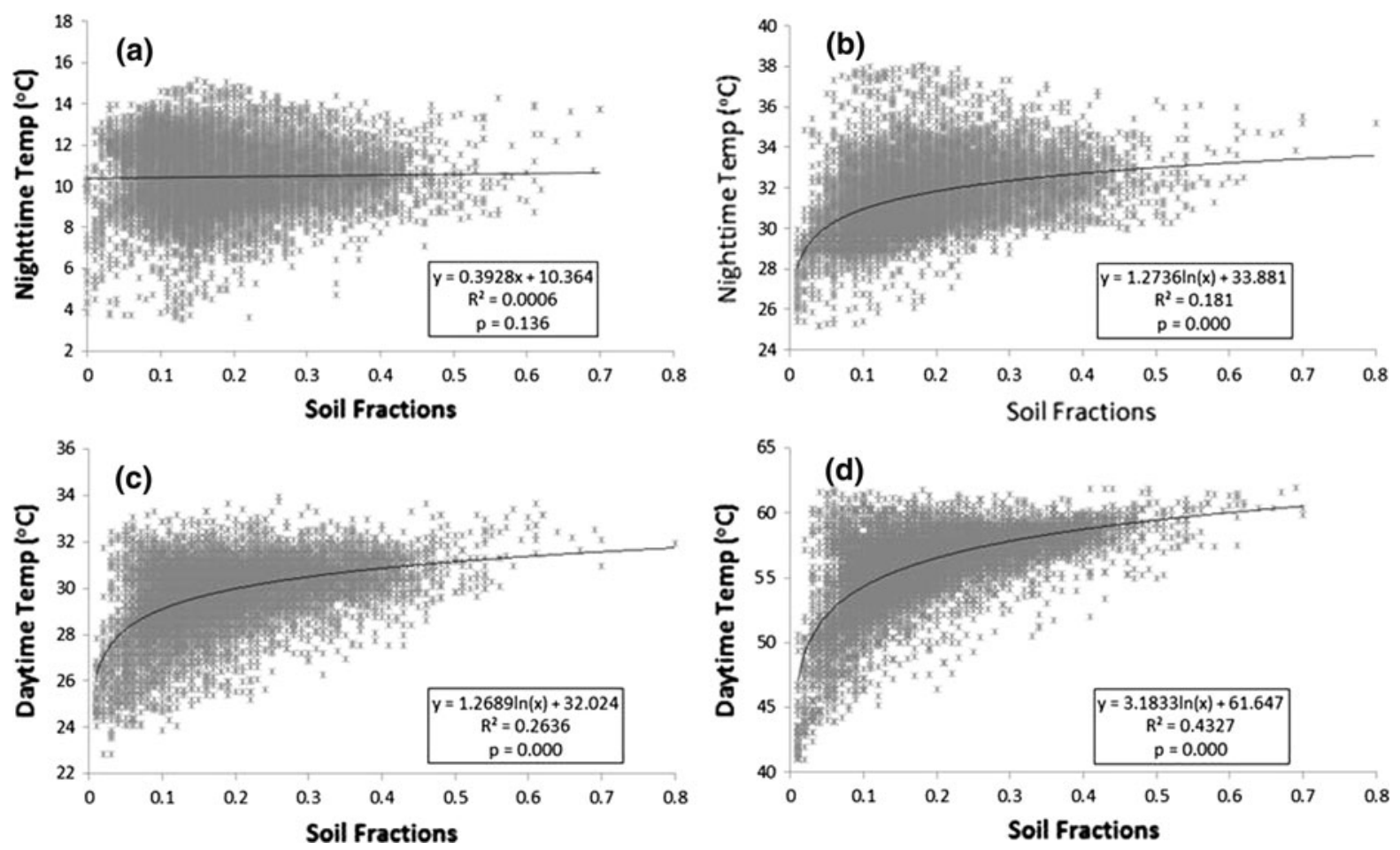

Fig. 13 Regression analysis between unmanaged soil fractions (x axis) and surface temperatures (y axis). a Unmanaged soil fractions versus nighttime temperature $\left({ }^{\circ} \mathrm{C}\right)$ (5 March 2007); b Unmanaged soil fractions versus nighttime temperature $\left({ }^{\circ} \mathrm{C}\right)$

surfaces together) and surface temperatures. It was observed that these relationships were not significant and the scatter plot did not show a clear pattern since each point (each pixel) under investigation was considered (Zhang et al. 2009; Myint et al. 2010; Li et al. 2011). The use of medium resolution data without the identification of different types of impervious surfaces could have led to this ambiguous pattern.

Following the preceding analyses and findings, it is appropriate to report that other impervious surfaces accelerate energy fluxes significantly whereas buildings serve as environmentally friendly materials to the UHI effect. This is probably due to the fact that most other impervious surfaces are made of dark surfaces, which is not the case for building rooftops and building materials in our study area. It should be noted that approximately $90 \%$ of all impervious surfaces in the United States are made of asphalt (dark surfaces) (EPA 2010). This is significant for other urban arid and semi-arid areas, both in the U.S. and globally.

(22 August 2005); c Unmanaged soil fractions versus daytime temperature $\left({ }^{\circ} \mathrm{C}\right)$ (27 February 2007); d Unmanaged soil fractions versus daytime temperature $\left({ }^{\circ} \mathrm{C}\right)$ (6 July 2005)

Contrary to another common perception, unmanaged soil fractions strongly influence daytime and nighttime temperatures both in the summer and winter (Fig. 13a-d). Their relationships are statistically significant at 0.01 . We observed that the relationships are non-linear. It was also observed that smaller soil fractions have a bigger impact on urban warming effect especially when dealing with daytime temperature in the summer (Fig. 13d). Unmanaged soil covers are as physically powerful as impervious surface areas in augmenting the UHI effect.

As stated earlier, we established multiple regression models to explore the combined effects of five independent variables (i.e., buildings, soil, grass, impervious, trees) together on surface temperatures. Table 5 indicates the proportion of the variance in the temperatures accounted for by our set of predictor variables (building, soil, grass, impervious, water, trees) for the multiple regression models for all selected ASTER images-6 July 2005, 22 August 2005, 27 February 2007, and 5 March 2007. The combined effects of predictor variables have more 
impact on surface temperatures in the summer since the summer day and night observations yield better overall multiple $\mathrm{R}^{2}$ than the winter observations.

For the winter March night (Table 5), it can be observed that all parameters strongly influence nighttime surface temperatures in the winter. Grass was negatively correlated to temperatures and the strongest variable among all. Other equally strong parameters that influence surface temperatures include impervious surface, trees and buildings. It should be noted that impervious surface elevated surface temperatures whereas buildings effectively lowered them during the winter night.

For the summer August night (Table 5), impervious surface, grass and unmanaged soil rank the highest

Table 5 Multiple regression statistics

\begin{tabular}{|c|c|c|c|c|c|}
\hline & Coef & SE & Beta & $\mathrm{t}$ & $p$ \\
\hline \multicolumn{6}{|c|}{ 5-March-07 (Nighttime), $\mathrm{R}^{2}=0.147, \mathrm{f}=379.9$} \\
\hline (Constant) & 10.728 & .150 & & 71.690 & 0.000 \\
\hline Buildings & -3.536 & .219 & -.166 & -16.167 & 0.000 \\
\hline Soil & -.287 & .203 & -.017 & -1.412 & 0.158 \\
\hline Grass & -3.655 & .216 & -.329 & -16.936 & 0.000 \\
\hline Impervious & 2.282 & .184 & .209 & 12.396 & 0.000 \\
\hline Trees & 6.367 & .325 & .277 & 19.610 & 0.000 \\
\hline \multicolumn{6}{|c|}{ 22-August-05 (Nighttime), $\mathrm{R}^{2}=0.681, \mathrm{f}=4,695.3$} \\
\hline (Constant) & 30.150 & .097 & & 310.127 & 0.000 \\
\hline Buildings & -2.321 & .142 & -.103 & -16.338 & 0.000 \\
\hline Soil & 3.356 & .132 & .190 & 25.421 & 0.000 \\
\hline Grass & -3.311 & .140 & -.281 & -23.613 & 0.000 \\
\hline Impervious & 6.625 & .120 & .572 & 55.388 & 0.000 \\
\hline Trees & 1.777 & .211 & .073 & 8.422 & 0.000 \\
\hline \multicolumn{6}{|c|}{ 27-February-07 (Daytime), $\mathrm{R}^{2}=0.365, \mathrm{f}=1,266.4$} \\
\hline (Constant) & 29.622 & .116 & & 256.185 & 0.000 \\
\hline Buildings & .739 & .169 & .039 & 4.373 & 0.000 \\
\hline Soil & 3.148 & .157 & .211 & 20.051 & 0.000 \\
\hline Grass & -.601 & .167 & -.060 & -3.606 & 0.000 \\
\hline Impervious & .812 & .142 & .083 & 5.710 & 0.000 \\
\hline Trees & -7.292 & .251 & -.355 & -29.063 & 0.000 \\
\hline \multicolumn{6}{|c|}{ 6-July-05 (Daytime), $\mathrm{R}^{2}=0.669, \mathrm{f}=4,452.6$} \\
\hline (Constant) & 55.715 & .162 & & 344.716 & 0.000 \\
\hline Buildings & 3.912 & .236 & .106 & 16.561 & 0.000 \\
\hline Soil & 7.594 & .219 & .263 & 34.603 & 0.000 \\
\hline Impervious & -7.015 & .233 & -.364 & -30.093 & 0.000 \\
\hline Water & 1.562 & .199 & .083 & 7.855 & 0.000 \\
\hline Trees & -9.337 & .351 & -.235 & -26.623 & 0.000 \\
\hline
\end{tabular}

among all independent variables with impervious surfaces, unmanaged soil and trees elevating surface temperatures and grass lowering them. For the other variables, buildings were found to lower nighttime surface temperatures in the summer whereas impervious surface strongly elevates nighttime temperatures. Please note that trees were positively correlated with nighttime temperatures in both winter and summer. This is slightly different from what we observed in the univariate models especially when dealing with summer night temperatures since the univariate model for winter night temperatures was not statistically significant. However, this finding is consistent with what was reported in Myint et al. (2010). Under and near tree canopies at night especially in the winter heat is retained more than open areas due to decreased sky view factors. On the other hand, solar radiation that can penetrate low crown closure during the day heats other man-made features that may not be able to radiate effectively and efficiently (Heisler et al. 1995).

For the winter February daytime temperatures (Table 5), most predictor variables do not have strong impacts on the dependent variable except the tree category. The regression results for the winter suggest that trees can effectively lower daytime temperatures whereas the grass category was not effective in decreasing temperatures. Buildings have the lowest or almost no impact on daytime temperatures in the winter. Unmanaged soil category was the second strongest variable significantly increasing daytime temperatures in the winter.

For the summer July day (Table 5), although all factors significantly relate to temperatures, the ranking of importance of those factors shows that the grass category had the greatest effect followed by unmanaged soil and trees. It was found that both grass and trees can lower temperatures effectively in summer days. Impervious surfaces had the least impact on summer day temperatures. In contrast, unmanaged soil drastically increases surface temperatures in the summer.

\section{Conclusions}

We conclude that the built environment as a whole does not explain the UHI effect in desert cities but that individual land covers contribute differently. This conclusion validates our assertion that generalized 
land use and vegetation indices from low-resolution remotely sensed data sources limits understanding of the drivers and consequences of the UHI. Future studies of the UHI should consider using highresolution data sources.

Specifically for Phoenix, we found that buildings alone do not contribute significantly to UHI and, in fact, demonstrate solar insulation qualities, unlike unmanaged soil and impervious surfaces that exhibit higher heat storage capacities. Asphalt surfaces, generally located near buildings, is the land cover class that exacerbates extreme heat. We also found that a more compact arrangement of commercial buildings does not result in more heat during the day, but actually enables more cooling at night due to the avoidance of heat storing impervious surfaces and more roof-level emittance of heat. In regards to residential buildings, we found that greater residential housing fraction tends to increase daytime surface temperatures but the impact at night is not significant. Trees tend to lower surface temperature more effectively than grass in these areas therefore lowering the UHI and potentially energy use in arid desert areas.

Beyond buildings, we found that unmanaged soils increase daytime temperatures at an increasingly high rate, and confirmed that dark impervious materials increase both daytime and nighttime surface temperatures significantly. From these results, we can surmise that reducing dark impervious surfaces and unmanaged soil areas would contribute to less heat as well. Finally, water bodies generally are negatively correlated to surface temperatures. However, our study showed that small water bodies, such as household swimming pools, do not effectively lower daytime surface temperatures and have no significant impact on nighttime temperatures due to their area coverage in comparison to surrounding urban environment. This indicates that these water bodies are not an efficient means of reducing UHI in desert cities. Finally, it is important to understand the relation between dark and bright materials in relation to surface temperatures in desert cities. Darker roofs and buildings absorb and retain heat longer than white or bright-colored roofs and buildings. Furthermore, materials such as metals and smooth surfaces absorb more heat when they are dark colored versus light colored and rough.

We conclude that desert city landscapes should be "built" using buildings, trees, shrubs, and bright materials to reduce temperatures. This conclusion can be drawn if our focus is solely to mitigate urban warming without considering the tradeoffs relative to other environmental factors, such as precipitation and bio-diversity (Georgescu et al. 2012; Buyantuyev and $\mathrm{Wu}$ 2012), socio-economic values (Jenerette et al. 2007; Buyantuyev and Wu 2010), ecosystem services (Jenerette et al. 2011) and unintended consequences, such as increased water use (Gober et al. 2010).

Acknowledgments This research was supported by the National Science Foundation (Grant SES-0951366, Decision Center for a Desert City II: Urban Climate Adaptation). Any opinions, findings, and conclusions or recommendations expressed in this material are those of the authors and do not necessarily reflect the views of the sponsoring agencies.

Open Access This article is distributed under the terms of the Creative Commons Attribution License which permits any use, distribution, and reproduction in any medium, provided the original author(s) and the source are credited.

\section{References}

Anderson J, Hardy EE, Roach JT, Witmer RE (1976) A land use and land cover classification system for use with remote sensor data USGS Professional Paper 964. Sioux Falls, SD

Arnfield AJ (2003) Two decades of urban climate research: a review of turbulence, exchanges of energy and water, and the Urban Heat Island. Int J Climatol 23:1-26

Benz UC, Hofmann P, Willhauck G, Lingenfelder I, Heynen M (2004) Multi-resolution, object-oriented fuzzy analysis of remote sensing data for GIS-ready information. ISPRS J Photogramm Remote Sens 58:239-258

Bonan GB (2002) Ecological climatology: concepts and applications. Cambridge University Press, Cambridge

Brabec E, Schulte S, Richards PL (2002) Impervious surfaces and water quality: a review of current literature and its implications for watershed planning. J Plan Lit 16(4): 499-514

Brazel AJ, Selover N, Vose R, Heisler G (2000) The tale of two climates: Baltimore and Phoenix LTER sites. Clim Res 15:123-135

Buyantuyev A, Wu J (2010) Urban heat islands and landscape heterogeneity: linking spatiotemporal variations in surface temperatures to land-cover and socioeconomic patterns. Landscape Ecol 25:17-33

Buyantuyev A, Wu J (2012) Urbanization diversifies land surface phenology in arid environments: interactions among vegetation, climatic variation, and land use pattern in the Phoenix metropolitan region, US. Landsc Urban Plan 105(2012):149-159

Carlson TN, Arthur ST (2000) The impact of land use-land cover changes due to urbanization on surface microclimate and hydrology: a satellite perspective. Global Planet Change 25:49-65 
Carlson TN, Augustine JA, Boland FE (1977) Potential application of satellite temperature measurements in the analysis of land use over urban areas. Bull Am Meteorol Soc 58:1301-1303

Dousset B (1989) AVHRR-derived cloudiness and surface temperature patterns over the Los Angeles area and their relationship to land use. Proceedings of IGARSS-89. IEEE, New York, pp 2132-2137

Dousset B, Gourmelon F (2003) Satellite multi-sensor data analysis of urban surface temperatures and land cover. ISPRS J Photogramm Remote Sens 58:43-54

EPA (2003) Beating the heat: mitigating thermal impacts. Nonpoint Source News Notes 72:23-26

EPA (2010) Title of page. http://www.epa.gov/heatisld/resour ces/glossary.htm. Last Accessed 27 May 2010

Georgescu M, Mahalov A, Moustaoui M (2012) Seasonal hydroclimatic impacts of Sun Corridor expansion. Environ Res Lett. doi:10.1088/1748-9326/7/3/034026

Gober P, Brazel A, Quay R, Myint SW, Grossman-Clarke S, Miller A, Rossi S (2010) Using watered landscapes to manipulate urban heat island effects: how much water will it take to cool Phoenix? J Am Plan Assoc 76:109-121

Grimmond CSB, Oke TR (2002) Turbulent heat fluxes in urban areas: observations and a local-scale urban meteorological parameterization scheme (LUMPS). J Appl Meteorol 41: $792-810$

Grossman-Clarke S, Zehnder JA, Stefanov WL, Liu YB, Zoldak MA (2005) Urban modifications in a mesoscale meteorological model and the effects on near-surface variables in an arid metropolitan region. J Appl Meteorol 44(9): 1281-1297

Guhathakurta S, Gober P (2010) Residential land use, the urban heat island, and water use in phoenix: a path analysis. J Plan Educ Res 30:40-51

Heisler GM, Grant RH, Grimmond S, Souch C (1995) Urban forests-cooling our communities? In: Kollin C, Barretts M (eds) Proceedings of the seventh national urban forest conference. American Forests, Washington, pp 31-34

Huang YJ, Akbari H, Taha H (1987) The potential of vegetation in reducing summer cooling loads in residential buildings. J Clim Appl Meteorol 26:1103-1116

Hucheon RJ, Johnson RH, Lowry WP, Black CH, Hadley D (1967) Observations of urban heat island in a small city. Bull Am Meteorol Soc 48(1):7-8

Hung T, Uchihama D, Ochi S, Yasuoka Y (2006) Assessment with satellite data of the urban heat island effects in Asian mega cities. Int J Appl Earth Obs Geoinf 8:34-48

Jenerette GD, Harlan SL, Brazel A, Jones N, Larsen L, Stefanov WL (2007) Regional relationships between surface temperature, vegetation, and human settlement in a rapidly urbanizing ecosystem. Landscape Ecol 22:353-365

Jenerette GD, Harlan SL, Stefanov WL, Martin CA (2011) Ecosystem services and urban heat risks cape moderation: water, green spaces, and social inequality in Phoenix, USA. Ecol Appl 21:2637-2651

Jensen JR (2004) Introductory digital image processing, a remote sensing perspectives. Prentice Hall, Upper Saddle River

Jensen JR, Cowen DC (1999) Remote sensing of urban/suburban infrastructure and socio-economic attributes. Photogramm Eng Remote Sens 65:611-622
JPL (2001) ASTER Higher-Level Product User Guide, Advanced Spaceborne Thermal Emission and Reflection Radiometer, Jet Propulsion Laboratory, California Institute of Technology, http://asterweb.jpl.nasa.gov/content/03_ data/04_Documents/ASTERHigherLevelUserGuideVer 2May01.pdf

Lee HY (1993) An application of NOAA-AVHRR thermal data to the study of urban heat islands. Atmos Environ 27B:1-13

Li JX, Song CH, Cao L, Zhu F, Meng X, Wu J (2011) Impacts of landscape structure on surface urban heat islands: a case study of Shanghai, China. Remote Sens Environ 115:3249-3263

Lillesand TM, Kiefer RW, Chipman JW (2008) Remote sensing and image interpretation. Wiley, New York

Myint SW (2006) Urban vegetation mapping using sub-pixel analysis and expert system rules: a critical approach. Int J Remote Sens 27:2645-2665

Myint SW, Brazel A, Okin G, Buyantuyev A (2010) An interactive function of impervious and vegetation covers in relation to the urban heat island effect in a rapidly urbanizing desert city. GISci Remote Sens 47(3):301-320

Myint SW, Gober P, Brazel A, Grossman-Clarke S, Weng Q (2011) Per-pixel versus object-based classification of urban land cover extraction using high spatial resolution imagery. Remote Sens Environ 115(2011):1145-1161

Oke TR (1973) City size and urban heat island. Atmos Environ 7:769-779

Oke TR (1981) Canyon geometry and the nocturnal urban heatisland-comparison of scale model and field observations. J Climatol 1:237-254

Oke TR (1982) The energetic basis of the urban heat island. Q J R Meteorol Soc 108:1-24

Olfe DB, Lee RL (1971) Linearized calculations of urban heat island convection effects. J Atmos Sci 28(8):1374-1388

Owen TW, Carlson TN, Gillies RR (1998) An assessment of satellite remotely-sensed land cover parameters in quantitatively describing the climatic effect of urbanization. Int $\mathbf{J}$ Remote Sens 19:1663-1681

Quattrochi DA, Ridd MK (1994) Measurement and analysis of thermal energy responses from discrete urban surfaces using remote sensing data. Int J Remote Sens 15:1991-2022

Sailor DJ (1995) Simulated urban climate response to modifications in surface albedo and vegetative cover. J Appl Meteorol 34:1694-1704

Spronken-Smith RA, Oke TR (1998) The thermal regime of urban parks in two cities with different summer climates. Int J Remote Sens 19:2085-2104

Stoll MJ, Brazel AJ (1992) Surface-air temperature relationships in the urban environment of Phoenix. Ariz Phys Geogr 13:160-179

Townshend JRG (1981) Terrain analysis and remote sensing. George Allen and Unwin, London $272 \mathrm{p}$

U.S. Department of Commerce (2010) http://www.wrh.noaa. gov/psr/general/safety/heat/, NOAA National Weather Forecast Service Office, Phoenix Weather Forecast Office. Accessed 9 Feb 2010

Voogt JA (2000) Image representations of urban surface temperatures. Geocarto Int 15:19-29

Voogt JA, Oke TR (1997) Complete urban surface temperatures. J Appl Meteorol 36:1117-1132

Voogt JA, Oke TR (2003) Thermal remote sensing of urban climates. Remote Sens Environ 86:370-384 
Walter V (2004) Object-based classification of remote sensing data for change detection. ISPRS J Photogramm Remote Sens 58:225-238

Weng Q, Lu D, Schubring J (2004) Estimation of land surface temperature-vegetation abundance relationship for urban heat island studies. Remote Sens Environ 89:467-483

Wilson JS, Clay M, Martin E, Stuckey D, Vedder-Risch K (2003) Evaluating environmental influences of zoning in urban ecosystems with remote sensing. Remote Sens Environ 86:303-321

Xian G (2006) Assessing urban growth with subpixel impervious surface coverage. In: Weng Q, Quattrochi DA (eds) Urban remote sensing. Taylor and Francis Group, Boca Raton, pp 179-199
Zhang X, Aono Y, Monji N (1998) Spatial variability of urban surface heat fluxes estimated from Landsat TM data under summer and winter conditions. J Agric Meteorol 54:1-11

Zhang Y, Odeh IOA, Han C (2009) Bi-temporal characterization of land surface temperature in relation to impervious surface area, NDVI and NDBI, using a sub-pixel image analysis. Int J Appl Earth Obs Geoinf 11:256-264

Zhou W, Huang G, Cadenaso ML (2011) Does the spatial configuration matter? Does spatial configuration matter? Understanding the effects of land cover pattern on land surface temperature in urban landscapes. Landsc Urban Plan 102(1):54-63 